Defraeye T., Blocken B., Carmeliet J. (2012), Analysis of convective heat and mass transfer coefficients for convective drying of a porous flat plate by conjugate modelling, International Journal of Heat and Mass Transfer 55 (1-3), 112-124. http://dx.doi.org/10.1016/j.ijheatmasstransfer.2011.08.047

\title{
Analysis of convective heat and mass transfer coefficients for convective drying of a porous flat plate by conjugate modelling
}

\author{
Thijs Defraeye ${ }^{\mathrm{a}, \mathrm{c} *}$, Bert Blocken ${ }^{\mathrm{b}}$, Jan Carmeliet ${ }^{\mathrm{c}, \mathrm{d}}$
}

${ }^{a}$ Laboratory of Building Physics, Department of Civil Engineering, Katholieke Universiteit Leuven, Kasteelpark Arenberg 40, 3001 Heverlee, Belgium

${ }^{b}$ Building Physics and Systems, Eindhoven University of Technology, P.O. Box 513, 5600 Eindhoven, The Netherlands

${ }^{c}$ Chair of Building Physics, Swiss Federal Institute of Technology Zurich (ETHZ), Wolfgang-Pauli-Strasse 15, 8093 Zürich, Switzerland

${ }^{d}$ Laboratory for Building Science and Technology, Swiss Federal Laboratories for Materials Testing and Research (Empa), Überlandstrasse 129, 8600 Dübendorf, Switzerland

\section{Keywords}

convective transfer coefficient; conjugate; porous material; computational fluid dynamics; drying; flat plate

\begin{abstract}
Convective drying of an unsaturated porous flat plate at low Reynolds numbers $\left(10^{3}\right)$ is analysed by means of conjugate modelling of heat and mass transport in the air flow and the porous material. Conjugate modelling does not require knowledge of convective transfer coefficients (CTCs) but allows determining the CTCs aposteriori, hence identifying their spatial and temporal variability, which is the main focus of this study. Comparison is made with porous-material modelling using spatially and/or temporally constant CTCs. Both spatial and temporal variations of the convective boundary conditions are found to have a distinct impact on the drying behaviour: the spatial CTC variation results in two-dimensional drying of the porous material due to leading-edge effects; the temporal CTC variation identifies distinct maxima in the drying rates at the surface right before the surface dries out locally. The CTCs obtained with conjugate modelling remain approximately constant during the constant and decreasing drying rate period (CDRP and DDRP, respectively), but a distinct variation is noticed at the transition of CDRP to DDRP. The heat and mass transfer analogy is found to be valid during the CDRP and to a lesser extent during the DDRP but large discrepancies are found during the transition of CDRP to DDRP. The advantages of conjugate modelling are indicated in this study but the need for detailed modelling of convective boundary conditions is however strongly dependent on the drying behaviour of the porous material and is not always required.
\end{abstract}

\section{Nomenclature}

$\mathrm{D}_{\mathrm{va}} \quad$ binary diffusion coefficient between dry air and water vapour, $\delta_{\mathrm{v}} \mathrm{R}_{\mathrm{v}} \mathrm{T}\left(\mathrm{m}^{2} / \mathrm{s}\right)$

\footnotetext{
${ }^{*}$ Corresponding author. Tel.: +32 (0)16321348; Fax: +32 (0)16321980

E-mail address: thijs.defraeye@bwk.kuleuven.be
}

This document is the accepted manuscript version of the following article:

Defraeye, T., Blocken, B., \& Carmeliet, J. (2012). Analysis of convective heat and mass transfer coefficients for convective drying of a porous flat plate by conjugate modelling. International Journal of Heat and Mass Transfer, 55(1), 1 112-124. http://doi.org/10.1016/j.ijheatmasstransfer.2011.08.047 
Defraeye T., Blocken B., Carmeliet J. (2012), Analysis of convective heat and mass transfer coefficients for convective drying of a porous flat plate by conjugate modelling, International Journal of Heat and Mass Transfer 55 (1-3), 112-124. http://dx.doi.org/10.1016/i.ijheatmasstransfer.2011.08.047

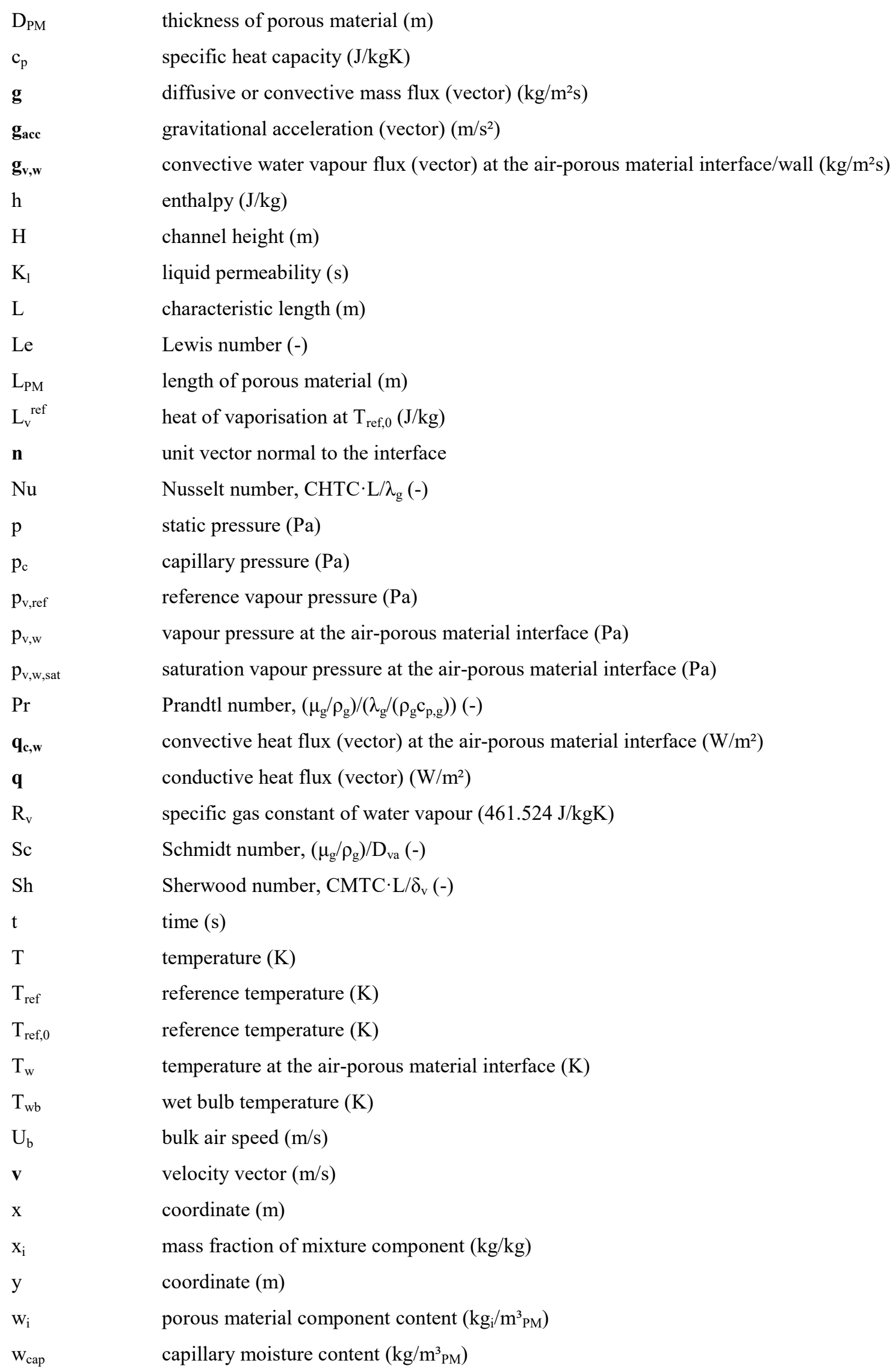


Defraeye T., Blocken B., Carmeliet J. (2012), Analysis of convective heat and mass transfer coefficients for convective drying of a porous flat plate by conjugate modelling, International Journal of Heat and Mass Transfer 55 (1-3), 112-124. http://dx.doi.org/10.1016/i.ijheatmasstransfer.2011.08.047

$\begin{array}{ll}\text { avg } & \text { surface-averaged } \\ \mathrm{AF}_{\mathrm{cc}} & \text { analogy factor based on the heat and mass transfer analogy (Chilton-Colburn analogy) } \\ \mathrm{AF}_{\mathrm{CDRP}} & \text { analogy factor based on CDRP drying } \\ \mathrm{CDRP} & \text { constant drying rate period } \\ \mathrm{CFD} & \text { computational fluid dynamics } \\ \text { CHTC } & \text { convective heat transfer coefficient } \\ \text { CMTC } & \text { convective mass transfer coefficient } \\ \text { CTC } & \text { convective transfer coefficient } \\ \text { DDRP } & \text { decreasing drying rate period } \\ \text { HAM } & \text { heat-air-moisture } \\ \text { RH } & \text { relative humidity }\end{array}$

Greek symbols

$\gamma$

$\delta_{\mathrm{v}}$

$\lambda$

$\mu$

$\mu_{\text {dry }}$

$\rho$

Subscripts

a

cc

CDRP

i

g

1

PM

ref

s

SC

$\mathrm{v}$

w

\section{Superscripts}

fl

pm normalised derivative of the surface tension to the temperature (-)

water vapour diffusion coefficient (s)

thermal conductivity $(\mathrm{W} / \mathrm{mK})$

dynamic viscosity $(\mathrm{kg} / \mathrm{ms})$

vapour resistance factor of the dry porous material (-)

density $\left(\mathrm{kg} / \mathrm{m}^{3}\right)$

dry air

Chilton Colburn

constant drying rate period

index indicating a specific mixture/material component

moist air (gas)

liquid water

porous material

reference condition

solid material matrix

scaled

water vapour

wall/ air-porous material interface

fluid

porous material 
Defraeye T., Blocken B., Carmeliet J. (2012), Analysis of convective heat and mass transfer coefficients for convective drying of a porous flat plate by conjugate modelling, International Journal of Heat and Mass Transfer 55 (1-3), 112-124. http://dx.doi.org/10.1016/j.ijheatmasstransfer.2011.08.047

\section{Introduction}

Convective drying of porous materials is of interest for many industrial applications [1], such as production of building materials (concrete, brick, gypsum board, ...), food processing or wood and paper production.

Optimisation of the drying process is required to enhance processing efficiency, in terms of energy usage and production time, without compromising the product quality, for example by excessive shrinkage or warping. Many numerical modelling approaches have been developed to model the coupled heat and moisture transport in porous materials, such as pore network models (e.g. [2-4]) or macroscopic models (e.g. [5,6]). In these models, the convective heat and mass exchange with the external air flow is often modelled by means of convective heat and mass transfer coefficients, i.e. CHTCs and CMTCs, respectively. These convective transfer coefficients (CTCs) relate the convective heat and moisture flux normal to the wall $\left(\mathrm{q}_{\mathrm{c}, \mathrm{w}}\right.$ and $\left.\mathrm{g}_{\mathrm{v}, \mathrm{w}}\right)$, i.e. the air-porous material interface, to the difference between the wall temperature $\left(T_{w}\right)$ or vapour pressure at the wall $\left(p_{v, w}\right)$ and a reference temperature $\left(\mathrm{T}_{\text {ref }}\right)$ or vapour pressure $\left(\mathrm{p}_{\mathrm{v}, \mathrm{ref}}\right)$, for example the approach flow conditions:

$$
\begin{aligned}
& \text { CHTC }=\frac{\mathrm{q}_{\mathrm{c}, \mathrm{w}}}{\mathrm{T}_{\mathrm{w}}-\mathrm{T}_{\text {ref }}} \\
& \text { CMTC }=\frac{\mathrm{g}_{\mathrm{c}, \mathrm{w}}}{\mathrm{p}_{\mathrm{v}, \mathrm{w}}-\mathrm{p}_{\mathrm{v}, \text { ref }}}
\end{aligned}
$$

The fluxes are assumed positive away from the porous material. CTCs however account for the convective exchange in a quite simplified way: (1) CTCs are often estimated by means of empirical correlations with the air speed, where these correlations were mostly derived for simplified configurations, such as flat plates; (2) The spatial variation of CTCs along the surface and especially their temporal variation are often not accounted for; (3) CMTCs are often estimated from CHTCs by using the heat and mass transfer analogy, hence assuming its validity throughout the entire drying process; (4) CTCs are strongly dependent on the reference conditions $\left(T_{\text {ref }}\right.$ and $p_{\mathrm{v}, \mathrm{ref}}$ ), but the location where these are evaluated is generally chosen rather arbitrary for complex flow problems.

Due to these simplifications, the use of CTCs can compromise the accuracy of fluid-side convective heat and mass transfer predictions for certain applications (e.g. [7-9]), one of them being convective drying of (un)saturated porous materials. Here, evaporation occurs initially at the air-porous material interface, by which mainly the air flow conditions, and not the porous-material properties, characterise the drying rate [1]. After an initial transition period, the material experiences the constant drying rate period (CDRP), given that the airporous material interface remains wet. The CDRP is characterised by a relative humidity (RH) of $100 \%$ at the surface, a constant drying rate and a constant material temperature, which is equal to the wet bulb temperature $\left(\mathrm{T}_{\mathrm{wb}}\right)$ if no radiative heat flows at the surface and (conductive) heat flows from the interior of the porous material are present. In this case, the convective heat supply to the interface is quasi entirely used for the evaporation of water (e.g. [10]):

$\mathrm{q}_{\mathrm{c}, \mathrm{w}} \approx-\mathrm{L}_{\mathrm{v}}^{\mathrm{ref}} \mathrm{g}_{\mathrm{v}, \mathrm{w}}$

where $\mathrm{L}_{\mathrm{v}}{ }^{\text {ref }}$ is the heat of vaporisation, also called latent heat, which is the energy needed for the phase change from liquid to vapour. Although the air flow (CTCs, $\mathrm{T}_{\mathrm{ref}}$ and $\mathrm{p}_{\mathrm{v}, \mathrm{ref}}$ ) characterises the CDRP, the porous-material transport properties however affect the duration of the transition period, i.e. the time to attain a quasi uniform 
Defraeye T., Blocken B., Carmeliet J. (2012), Analysis of convective heat and mass transfer coefficients for convective drying of a porous flat plate by conjugate modelling, International Journal of Heat and Mass Transfer 55 (1-3), 112-124. http://dx.doi.org/10.1016/j.ijheatmasstransfer.2011.08.047

temperature distribution in the porous material, and also the duration of the CDRP, which is dependent on the liquid transport to the surface. When the material dries out locally at the interface, the decreasing drying rate period (DDRP) sets in, which is characterised by a lower drying rate since the "dry" outer porous-material layer forms an additional resistance to liquid water removal from the inside of the material, where it evaporates, towards the interface, in addition to the boundary-layer resistance. This decrease in drying rate results in a temperature increase since less heat is required for the evaporation of water. During the DDRP, the convective boundary conditions are less critical by which a lower accuracy of the CTCs does not necessarily disturb a reliable simulation [11].

A more detailed evaluation of the convective boundary conditions than by means of simplified CTCs could enhance the numerical predictive accuracy for convective drying processes, especially during the CDRP and the transition to the DDRP. Therefore, several numerical models were developed recently which solve the conjugate problem, i.e. accounting simultaneously for heat and mass transport in both the porous material and the air flow (e.g. [12-16]). Such models avoid using CTCs since the air flow is explicitly solved to some extent. They were used to evaluate and optimise drying processes by analysing the influence of the flow parameters (temperature, relative humidity and velocity), buoyancy, bound water transport, etc. on the drying time and rate, but also the validity of the heat and mass transfer analogy and spatial inhomogeneities in drying fronts were considered.

In this study such a conjugate model is developed and used to simulate and analyse convective drying of an unsaturated porous flat plate at low Reynolds numbers. The focus of this study is specifically on CTCs, where the spatial and also the temporal variation of these CTCs, obtained a-posteriori from the conjugate model results, are evaluated. Comparison is made to porous-material modelling using spatially and/or temporally constant CTCs. Furthermore, the validity of the heat and mass transfer analogy is investigated.

\section{Conjugate model}

\subsection{Air-flow modelling}

Air flow is modelled by solving the Navier-Stokes equations, i.e. the conservation equations of mass, momentum and energy. Only a gaseous phase is assumed to exist where moist air (subscript $\mathrm{g}_{\mathrm{g}}$ ) is considered to be a perfect mixture of two ideal gases, namely dry air (subscript ${ }_{\mathrm{a}}$ ) and water vapour (subscript ${ }_{\mathrm{v}}$ ). Furthermore, it is assumed that: (1) the mixture is dilute, in terms of water vapour; (2) moist air is incompressible; (3) thermal equilibrium between the mixture components exists; (4) no volumetric mass, momentum or heat source terms are present; (5) Soret and Dufour effects can be neglected; (6) viscous heat dissipation can be neglected; (7) pressure variations are sufficiently small to not affect thermodynamic properties; (8) potential and kinetic energy changes are negligible compared to thermal energy changes; (9) pressure work can be neglected. Thereby, following well-known conservation equations can be derived (see [17] for details).

\section{Conservation of mass}

$$
\frac{\partial \rho_{\mathrm{i}}}{\partial \mathrm{t}}+\nabla \cdot\left(\rho_{\mathrm{i}} \mathbf{v}_{\mathrm{i}}\right)=0
$$


where $\rho$ is the density, $\mathbf{v}$ is the velocity vector (bold characters are used to indicate vector quantities) and $i$ is an index, indicating a mixture component. The assumption of incompressible flow leads to:

$\nabla \cdot \mathbf{v}_{\mathbf{g}}=0$

The moist air density $\left(\rho_{\mathrm{g}}\right)$ and velocity $\left(\mathbf{v}_{\mathbf{g}}\right)$ are defined as:

$\rho_{\mathrm{g}}=\rho_{\mathrm{a}}+\rho_{\mathrm{v}}$

$\mathbf{v}_{\mathrm{g}}=\mathrm{x}_{\mathrm{a}} \mathbf{v}_{\mathrm{a}}+\mathrm{x}_{\mathrm{v}} \mathbf{v}_{\mathrm{v}}$

where $x_{i}$ is the mass fraction $\left(=\rho_{i} / \rho_{g}\right)$. The resulting mass fluxes of the mixture components $\mathbf{g}_{\mathbf{i}}\left(=\rho_{i} \mathbf{v}_{\mathbf{i}}\right)$ are defined as the sum of the convective $\left(=\rho_{\mathrm{i}} \mathbf{v}_{\mathrm{g}}\right)$ and diffusive fluxes:

$\mathbf{g}_{\mathbf{i}}=\rho_{\mathrm{i}} \mathbf{v}_{\mathbf{g}}-\rho_{\mathrm{g}} \mathrm{D}_{\mathrm{va}} \nabla \frac{\rho_{\mathrm{i}}}{\rho_{\mathrm{g}}}$

where $\mathrm{D}_{\mathrm{va}}$ is the binary diffusion coefficient between dry air and water vapour.

\section{Conservation of momentum}

$\rho_{\mathrm{g}} \frac{\partial}{\partial \mathrm{t}}\left(\mathbf{v}_{\mathbf{g}}\right)+\rho_{\mathrm{g}} \mathbf{v}_{\mathbf{g}} \cdot \nabla \mathbf{v}_{\mathbf{g}}=-\nabla \mathrm{p}+\mu_{\mathrm{g}} \nabla^{2} \mathbf{v}_{\mathbf{g}}+\rho_{\mathrm{g}} \mathbf{g}_{\mathbf{a c c}}$

where $\mu_{\mathrm{g}}$ is the dynamic viscosity, $\mathrm{p}$ is the static pressure and $\mathbf{g}_{\mathrm{acc}}$ is the gravitational acceleration.

\section{Conservation of energy}

$\frac{\partial}{\partial t}\left(\rho_{\mathrm{a}} \mathrm{h}_{\mathrm{a}}+\rho_{\mathrm{v}} \mathrm{h}_{\mathrm{v}}\right)+\nabla \cdot\left(\rho_{\mathrm{a}} \mathrm{h}_{\mathrm{a}} \mathbf{v}_{\mathbf{a}}+\rho_{\mathrm{v}} \mathrm{h}_{\mathrm{v}} \mathbf{v}_{\mathbf{v}}\right)=-\nabla \cdot\left(\mathbf{q}_{\mathbf{g}}\right)$

where $\mathbf{q}_{\mathbf{g}}$ is the conductive heat flux, which is defined as:

$\mathbf{q}_{\mathrm{g}}=-\lambda_{\mathrm{g}} \nabla \mathrm{T}$

where $\lambda_{\mathrm{g}}$ is the thermal conductivity of moist air. The enthalpies are defined as:

$\mathrm{h}_{\mathrm{a}}=\mathrm{c}_{\mathrm{p}, \mathrm{a}}\left(\mathrm{T}-\mathrm{T}_{\text {ref }, 0}\right)$

$\mathrm{h}_{\mathrm{v}}=\mathrm{c}_{\mathrm{p}, \mathrm{v}}\left(\mathrm{T}-\mathrm{T}_{\text {ref }, 0}\right)+\mathrm{L}_{\mathrm{v}}^{\mathrm{ref}}$

$h_{g}=x_{a} h_{a}+x_{v} h_{v}$

where $c_{p}$ is the specific heat capacity and $T_{\text {ref }, 0}$ is a reference temperature, taken equal to $273.15 \mathrm{~K}\left(0^{\circ} \mathrm{C}\right)$. The latent heat is defined with respect to $\mathrm{T}_{\mathrm{ref}, 0}$ and is assumed constant, namely equal to $2.50 \times 10^{6} \mathrm{~J} / \mathrm{kg}$ at $0^{\circ} \mathrm{C}$. These conservation equations for air flow are solved numerically with the commercial computational fluid dynamics (CFD) code Fluent 6.3 [18], which uses the control volume method.

\subsection{Porous-material modelling}

The porous material (subscript ${ }_{\mathrm{PM}}$ ) is modelled on a macroscopic level, i.e. by solving the macroscopic conservation equations, which can be derived by volume-averaging the microscopic conservation equations of each phase [19] or by adopting a phenomenological approach on a macroscopic level [20,21]. The porous materials consists of three different incompressible phases: the solid phase ( subscript $_{\mathrm{s}}$ ), namely the solid material matrix, the liquid phase (subscript ${ }_{1}$ ), namely liquid water, and the gaseous phase (subscript ${ }_{g}$ ), namely 
Defraeye T., Blocken B., Carmeliet J. (2012), Analysis of convective heat and mass transfer coefficients for convective drying of a porous flat plate by conjugate modelling, International Journal of Heat and Mass Transfer 55 (1-3), 112-124. http://dx.doi.org/10.1016/j.ijheatmasstransfer.2011.08.047

moist air, which again consists of dry air and water vapour. Thereby, four material components ( subscript $_{i}$ ) are found. Furthermore, it is assumed that: (1) liquid water is free water, so no chemically or physically bound water is taken into account; (2) the solid matrix is rigid, by which shrinking and swelling are not taken into account; (3) no volumetric heat and mass source terms, apart from evaporation or condensation of liquid water, are present; (4) thermal equilibrium between all phases exists; (5) pressure variations are sufficiently small to not affect thermodynamic properties; (6) potential and kinetic energy changes in the gaseous phase are negligible compared to thermal energy changes; (7) pressure work and viscous heat dissipation can be neglected; (8) liquid transport is driven by capillary forces, by which gravitational effects and air-pressure effects are neglected; (9) liquid transfer due to thermal gradients can be neglected; (10) the pressure of the gaseous phase is constant and equal to the atmospheric pressure; (11) temperatures are above $0^{\circ} \mathrm{C}$ and well below $100^{\circ} \mathrm{C} ;(12)$ the gaseous phase does not contribute to heat or mass storage; (13) moisture storage is independent of temperature; (14) radiative transfer inside the porous material is accounted for in its thermal conductivity. Thereby, following conservation equations can be derived [6,17], by expanding to the temperature $(T)$ and the capillary pressure $\left(\mathrm{p}_{\mathrm{c}}\right)$, where $p_{c}=p_{1}-p_{g}$.

\section{$\underline{\text { Conservation of mass }}$}

$$
\begin{aligned}
& \frac{\partial \mathrm{w}_{\mathrm{s}}}{\partial \mathrm{t}}=0 \\
& \frac{\partial \mathrm{w}_{\mathrm{a}}}{\partial \mathrm{t}}=0 ; \nabla \cdot \mathbf{g}_{\mathbf{a}}=0 \\
& \frac{\partial \mathrm{w}_{\mathrm{PM}}}{\partial \mathrm{p}_{\mathrm{c}}} \frac{\partial \mathrm{p}_{\mathrm{c}}}{\partial \mathrm{t}}+\nabla \cdot\left(\mathbf{g}_{\mathrm{l}}+\mathbf{g}_{\mathrm{v}}\right)=0
\end{aligned}
$$

where the liquid and water vapour fluxes are:

$$
\mathbf{g}_{\mathbf{l}}=-\mathrm{K}_{1} \nabla \mathrm{p}_{\mathrm{c}}
$$

$\mathbf{g}_{\mathbf{v}}=-\frac{\delta_{\mathrm{v}} \mathrm{p}_{\mathrm{v}}}{\rho_{\mathrm{l}} \mathrm{R}_{\mathrm{v}} \mathrm{T}} \nabla \mathrm{p}_{\mathrm{c}}-\frac{\delta_{\mathrm{v}} \mathrm{p}_{\mathrm{v}}}{\rho_{\mathrm{l}} \mathrm{R}_{\mathrm{v}} \mathrm{T}^{2}}\left(\rho_{\mathrm{l}} \mathrm{L}_{\mathrm{v}}^{\mathrm{ref}}+\mathrm{p}_{\mathrm{c}}(\gamma \mathrm{T}-1)\right) \nabla \mathrm{T}$

where $\mathrm{w}_{\mathrm{s}}, \mathrm{w}_{\mathrm{a}}$ and $\mathrm{w}_{\mathrm{PM}}$ are the solid matrix content, dry air content and moisture content of the porous material, respectively. Note that these quantities, defined in $\mathrm{kg}_{\mathrm{i}} / \mathrm{m}^{3}{ }_{\mathrm{PM}}$, differ from the densities of the different components $\left(\mathrm{kg}_{\mathrm{i}} / \mathrm{m}_{\mathrm{i}}^{3}\right) . \mathrm{K}_{1}$ is the liquid permeability, $\delta_{\mathrm{v}}$ is the water vapour diffusion coefficient, $\mathrm{R}_{\mathrm{v}}$ is the specific gas constant of water vapour and $\gamma$ is the normalised derivative of the surface tension to the temperature. These conservation equations imply that only heat and moisture transport are modelled, where dry air transport is not (Eq.(16)). In Eq.(19), the first term on the right hand side represents the vapour transport due to capillary pressure gradients and the second term represents the vapour transport due to thermal gradients, originating from evaporation and surface tension effects.

\section{Conservation of energy}

$\mathrm{h}_{1} \frac{\partial \mathrm{w}_{\mathrm{PM}}}{\partial \mathrm{p}_{\mathrm{c}}} \frac{\partial \mathrm{p}_{\mathrm{c}}}{\partial \mathrm{t}}+\left(\mathrm{c}_{\mathrm{p}, \mathrm{s}} \mathrm{w}_{\mathrm{s}}+\mathrm{c}_{\mathrm{p}, \mathrm{l}} \mathrm{w}_{\mathrm{PM}}\right) \frac{\partial \mathrm{T}}{\partial \mathrm{t}}+\nabla \cdot\left(\mathrm{h}_{1} \mathbf{g}_{\mathrm{l}}+\mathrm{h}_{\mathrm{v}} \mathbf{g}_{\mathrm{v}}\right)=-\nabla \cdot \mathbf{q}_{\mathbf{P M}}$

where $\mathbf{q}_{\mathbf{P M}}$ is the conductive heat flux, which is defined as: 
Defraeye T., Blocken B., Carmeliet J. (2012), Analysis of convective heat and mass transfer coefficients for convective drying of a porous flat plate by conjugate modelling, International Journal of Heat and Mass Transfer 55 (1-3), 112-124. http://dx.doi.org/10.1016/j.ijheatmasstransfer.2011.08.047

$\mathbf{q}_{\mathbf{P M}}=-\lambda_{\mathrm{PM}} \nabla \mathrm{T}$

The enthalpy of liquid water is defined as:

$\mathrm{h}_{1}=\mathrm{c}_{\mathrm{p}, 1}\left(\mathrm{~T}-\mathrm{T}_{\mathrm{ref}, 0}\right)$

The macroscopic approach considers the porous material as a continuum, where effective (macroscopic) transport coefficients (such as liquid permeability, vapour diffusion coefficient, ...) are required in the macroscopic conservation equations to numerically model the transport processes. Apart from the aforementioned modelling assumptions, material characterisation will thereby also determine the accuracy of numerical simulations, where a large sensitivity to these transport coefficients can be found [17]. These transport coefficients are usually determined experimentally, often as a function of the moisture content. A significant spread and thus uncertainty on these coefficients has however been reported when comparing results of different laboratories on multiple material samples [22,23].

The macroscopic conservation equations are solved numerically with a non-commercial finite-element heat-airmoisture (HAM) code HAMFEM [6].

\subsection{Conjugate modelling}

\subsubsection{Boundary conditions at the air-porous material interface}

The air-porous material interface can be modelled as: (1) a semi-permeable surface, implying that only transport of one gaseous mixture component (i.e. water vapour) from/to the surface is possible, which is the case for a free water surface or a fully-saturated porous material; or (2) a permeable surface, where dry air transport from/into the material can occur in addition to water vapour transport, such as for a quasi dry open-porous material. The choice of interface modelling is thereby related to the air permeability of the material.

A fully-saturated porous material is obviously impermeable for air [24]. Fully-saturated conditions are usually found during the production process of materials (e.g. concrete, brick, plaster). Apart from saturating the material in vacuum, obtaining a fully-saturated material a-posteriori requires submersion of the material for a sufficiently long time so all enclosed air is removed by diffusion through the liquid-filled pores. Thereby, wetted porous materials, such as building facades wetted by wind-driven rain, will often be unsaturated at the start of their drying process. For such unsaturated materials, Descamps [25] found that the critical moisture content for air transport, i.e. above which the air permeability is quasi zero, was slightly higher (roughly $10 \%$ ) than the capillary moisture content of the material, where the capillary moisture content can be obtained from a free water uptake test (e.g. [22]). For moisture contents below or equal to the capillary moisture content (i.e. capillary saturated), the porous material can be considered quasi permeable for air. Every gas pressure build-up is thus quickly equalised, leading to a constant air pressure in the porous material (e.g. [12]), which was also assumed in the porous-material model (section 2.2). Thereby $\mathrm{v}_{\mathrm{g}}=0$, resulting only in diffusive dry air and water vapour transport, where a zero net mass flow is found over the interface of a permeable surface, $\left(g_{g}=g_{a}+g_{v}=0\right)$. The proposed conjugate model was primarily developed for unsaturated porous materials, namely to analyse the 
Defraeye T., Blocken B., Carmeliet J. (2012), Analysis of convective heat and mass transfer coefficients for convective drying of a porous flat plate by conjugate modelling, International Journal of Heat and Mass Transfer 55 (1-3), 112-124. http://dx.doi.org/10.1016/j.ijheatmasstransfer.2011.08.047

drying of building materials in building envelopes, and therefore a permeable air-porous material interface will be assumed with material moisture contents equal to or below the capillary moisture content.

Conjugate modelling requires continuity of the boundary conditions at the air-porous material interface (fluidside: superscript ${ }^{\mathrm{fl}}$; porous-material side: superscript ${ }^{\mathrm{pm}}$ ). This implies continuity of the heat and mass fluxes for a specific boundary interface element as well as continuity of the temperature and mass fraction at the interface:

\section{Continuity of mass fluxes}

$\mathbf{g}_{\mathrm{a}}^{\mathrm{pm}} \cdot \mathbf{n}=\mathbf{g}_{\mathrm{a}}^{\mathrm{fl}} \cdot \mathbf{n}$

$\left(\mathbf{g}_{\mathrm{v}}^{\mathrm{pm}}+\mathbf{g}_{\mathbf{l}}^{\mathrm{pm}}\right) \cdot \mathbf{n}=\mathbf{g}_{\mathrm{v}}^{\mathrm{fl}} \cdot \mathbf{n}$

where $\mathbf{n}$ is the unit vector normal to the interface, $\mathbf{g}_{1}{ }^{p \mathbf{m}}$ and $\mathbf{g}_{\mathbf{v}}{ }^{p \mathbf{m}}$ are given by Eqs.(18)-(19), $\mathbf{g}_{\mathbf{v}}{ }^{\mathbf{f l}}$ is given by Eq.(8) and $\mathbf{g}_{\mathbf{a}}{ }^{\mathrm{h}} \cdot \mathbf{n}=-\mathbf{g}_{\mathbf{v}}{ }^{\mathrm{fl}} \cdot \mathbf{n}$ (permeable surface). Note that in the derivation of the porous-material model, dry air transport was neglected (section $2.2, \mathbf{g}_{\mathbf{a}}{ }^{\mathbf{p m}}=0$ ) by which the continuity of dry air fluxes at the interface is not satisfied. To retain consistency with the porous-material model, this dry air flux into the porous material $\left(\mathrm{g}_{\mathbf{a}}{ }^{\mathrm{pm}} \cdot \mathbf{n}\right)$ is thereby not accounted for in the conjugate model. The impact on the overall (heat and) moisture transport in the material and thus also on the convective (heat and) moisture exchange with the air flow can be considered very limited which is why it is actually neglected in the porous-material model, also referred to as the HAM model.

\section{Continuity of heat fluxes}

$\left(\mathrm{h}_{\mathrm{a}} \mathbf{g}_{\mathrm{a}}^{\mathbf{p m}}+\mathrm{h}_{\mathrm{v}} \mathbf{g}_{\mathrm{v}}^{\mathbf{p m}}+\mathrm{h}_{\mathrm{l}} \mathbf{g}_{\mathrm{l}}^{\mathbf{p m}}+\mathbf{q}_{\mathbf{P M}}\right) \cdot \mathbf{n}=\left(\mathrm{h}_{\mathrm{a}} \mathbf{g}_{\mathrm{a}}^{\mathbf{f l}}+\mathrm{h}_{\mathrm{v}} \mathbf{g}_{\mathrm{v}}^{\mathrm{fl}}+\mathbf{q}_{\mathrm{g}}\right) \cdot \mathbf{n}$

The influence of dry air transport on heat transport is neglected in the derivation of the porous-material model (section 2.2, $\mathbf{g}_{\mathbf{a}}{ }^{\mathbf{p m}}=0$ ) by which the continuity of heat fluxes at the interface is not entirely satisfied.

However, the influence of dry air transport on the heat (and mass) transport in the porous material and thus on the convective heat (and moisture) exchange with the air flow is very small. The assumption of a permeable or semi-permeable surface will thus actually have limited impact on the convective heat and moisture exchange at the interface. Note that the interface is thus modelled as a semi-permeable surface in this study to be in agreement with the actual physics of the air transport at the interface for moisture contents equal to or below the capillary moisture content. Nevertheless, semi-permeable conditions could not be entirely satisfied at the interface (i.e. on the porous-material side) since air transport in the porous material was not modelled in the porous-material model.

Continuity of temperature and mass fraction at the interface

$$
\begin{aligned}
& \mathrm{T}_{\mathrm{w}}^{\mathrm{pm}}=\mathrm{T}_{\mathrm{w}}^{\mathrm{fl}} \\
& \mathrm{x}_{\mathrm{w}}^{\mathrm{pm}}=\mathrm{x}_{\mathrm{w}}^{\mathrm{fl}}
\end{aligned}
$$

Note that the continuity of the pressure is not required since air transport in the porous material is not taken into account and only liquid water transport due to capillary forces is considered, neglecting the influence of gravitational and air-pressure effects. 
Defraeye T., Blocken B., Carmeliet J. (2012), Analysis of convective heat and mass transfer coefficients for convective drying of a porous flat plate by conjugate modelling, International Journal of Heat and Mass Transfer 55 (1-3), 112-124. http://dx.doi.org/10.1016/j.ijheatmasstransfer.2011.08.047

\subsubsection{Coupling principle}

Since two different programs are used for air-flow and porous-material modelling (Fluent 6.3 and HAMFEM), an external coupling protocol between these programs is required. An explicit coupling procedure, where the exchange of boundary conditions between the two programs is only performed once every time step, is preferred over an implicit coupling procedure, where iterations are performed between the two programs until convergence is obtained within a specific time step, for reasons of numerical implementation. Thereby, the CFD program is executed for one time step, after which boundary condition information (heat and moisture fluxes) is transferred to the HAM program which is subsequently executed for the same time step. At the end of this time step, boundary condition information (temperatures and vapour pressures) is transferred to the CFD program, which is used for the calculation of the next time step. This explicit coupling is justified if sufficiently small time steps are used (e.g. 0.1s) so the actual fluxes do not change significantly over the time step. This explicit coupling procedure is implemented within the HAM code, due to restricted access to the CFD code. The implementation and coupling procedure of the conjugate model are explained more in detail in Defraeye [17].

\section{Case study: Porous flat plate in channel flow}

\subsection{Configuration}

The configuration used to evaluate convective drying of an unsaturated porous material is taken from the experimental study of James et al. [26], where hygroscopic buffering of gypsum boards was analysed by means of a small closed-circuit wind-tunnel setup. Here, two-dimensional fully-developed laminar channel flow (channel height $\mathrm{H}=20.5 \mathrm{~mm}$ ) was produced over the porous material (length $\mathrm{L}_{\mathrm{PM}}=500 \mathrm{~mm}$ and thickness $\mathrm{D}_{\mathrm{PM}}$ $=37.5 \mathrm{~mm}$, i.e. 3 gypsum boards of $12.5 \mathrm{~mm}$ ), which was mounted flush with one of the channel walls. The porous material was insulated (adiabatic conditions) and made impermeable for moisture on its remaining surfaces. This setup is described in detail by Talukdar et al. [27].

The porous material considered in this study is a mineral plaster, which is a hygroscopic and capillary active material. Note that the same porous-material dimensions as in James et al. [26] are used. This mineral plaster, used in outdoor environments, can absorb liquid water coming from wind-driven rain, i.e. rain which is given a horizontal velocity component by wind (Blocken and Carmeliet [28]). For these conditions, its moisture content will be below or equal to the capillary moisture content (fully-saturated conditions are only obtained during processing of wet plaster). In this study, the mineral plaster is assumed to be initially at capillary moisture content. The relevant material properties, used for numerical modelling, are specified in Table 1. The liquid permeability is given in Figure 1.

\subsection{Numerical model}

The computational model used for the numerical analysis is presented in Figure 2, together with the imposed boundary conditions. A two-dimensional model can be used since the channel width to height ratio is 14.5 [29]. The length of the upstream and downstream channel sections is taken sufficiently large to avoid an influence of 
Defraeye T., Blocken B., Carmeliet J. (2012), Analysis of convective heat and mass transfer coefficients for convective drying of a porous flat plate by conjugate modelling, International Journal of Heat and Mass Transfer 55 (1-3), 112-124. http://dx.doi.org/10.1016/j.ijheatmasstransfer.2011.08.047

the imposed boundary conditions at the channel inlet and outlet on the air flow in the vicinity of the porous material. At the channel inlet, a fully-developed laminar inlet profile is imposed with a bulk air speed $\left(U_{b}\right)$ of 0.8 $\mathrm{m} / \mathrm{s}$, which results in a Reynolds number of about 1100, based on $\mathrm{U}_{\mathrm{b}}$ and $\mathrm{H}$. According to Dean [29], flow in two-dimensional channels remains laminar up to Reynolds numbers of about 1300. The temperature and relative humidity of the approach flow air are $23.8^{\circ} \mathrm{C}$ and $71.9 \%$, respectively. At the outlet of the computational domain, a zero static pressure is imposed. Both channel walls are modelled as no-slip boundaries with zero roughness. Apart from the interface with the porous material, the channel walls and the remaining porousmaterial boundaries are taken adiabatic and impermeable for moisture. The porous material is assumed to be initially unsaturated, but at capillary moisture content $\left(126 \mathrm{~kg} / \mathrm{m}^{3}\right)$ at a temperature of $20.0^{\circ} \mathrm{C}$. This temperature is chosen approximately equal to the wet bulb temperature $\left(\approx 20^{\circ} \mathrm{C}\right.$ for $\mathrm{T}_{\text {ref }}=23.8^{\circ} \mathrm{C}$ and $\left.\mathrm{RH}_{\text {ref }}=71.9 \%\right)$ in order to minimise the transition period for the material to reach the CDRP equilibrium temperature conditions.

Appropriate grids are built for air-flow and porous-material modelling, based on grid sensitivity analysis. The grids consist of $3.7 \times 10^{3}$ quadrilateral control volumes for air flow and of $2.5 \times 10^{3}$ quadrilateral finite elements for the porous material (125 in $\mathrm{x}$-direction, 20 in y-direction), both with a gradual refinement towards the air-porous material interface. At the interface, the control volumes and the finite elements have the same grid size (along xdirection), which was required for modelling purposes.

\subsection{Numerical simulation}

The air-flow simulations are performed assuming laminar flow, due to the low Reynolds numbers. Second-order discretisation schemes are used. The SIMPLE algorithm is used for pressure-velocity coupling. Pressure interpolation is second order. Since the Richardson number is well below one, buoyancy effects are negligible, as also mentioned by Talukdar et al. [30]. Thereby, only forced convection is accounted for in the air-flow simulations, considering heat as a passive scalar, by which the flow field and thus also the CTCs are not strongly dependent on the thermal boundary conditions. Radiation between the channel walls is not considered because the focus is on convective drying and the validity of the heat and mass transfer analogy, where the latter cannot be valid if radiation is taken into account (see section 4.3). Due to the low Reynolds numbers used in this test setup, radiation can however have an influence on the predicted drying rate. Note that, although laminar flow is considered in this study, also turbulent flow can be accounted for with the CFD code. The porous-material simulations are performed with a HAM model, where detailed numerical modelling details can be found in Janssen et al. [6]. The time step size used for the explicit coupling between CFD and HAM is determined by a temporal sensitivity analysis (see Defraeye [17]) and has an order of magnitude of about $10^{-1} \mathrm{~s}$.

The implementation of the conceptual model, i.e. the proposed conjugate model (section 2), into a computational model, i.e. the coupled CFD-HAM program, has to be verified (e.g. Franke et al. [31]) to make sure that there are no programming errors. Since both codes (CFD and HAM) were already verified separately by their code developers and no additional physical models are included in these separate codes, only the implementation of the coupling protocol between both codes was verified (see Defraeye [17]). 
Defraeye T., Blocken B., Carmeliet J. (2012), Analysis of convective heat and mass transfer coefficients for convective drying of a porous flat plate by conjugate modelling, International Journal of Heat and Mass Transfer 55 (1-3), 112-124. http://dx.doi.org/10.1016/j.ijheatmasstransfer.2011.08.047

Since the proposed conjugate model does not introduce additional physical models, as it is actually a coupling procedure between two existing computational models, validation of this conjugate model would reduce to a validation of the air-flow and porous-material models separately: discrepancies with experimental results would be attributed to the (in)ability of one of these models (or both) to capture the physics of the problem which it solves for, i.e. heat and moisture transport in the air flow or in the porous material. Validation of these air-flow and porous-material models was already performed in the past (e.g. Janssen et al. [6] for HAM and Defraeye et al. [8] for CFD) and is therefore not repeated here. Furthermore, performing a completely conjugate validation experiment is not straightforward since both heat and mass transport should be quantified simultaneously in the air flow, in the porous material and at the interface. Even with the current experimental techniques, it is still quite challenging to measure these quantities simultaneously in a (quasi) non-destructive, (quasi) non-intrusive way at a spatial resolution which is sufficient for detailed comparison with numerical simulation data.

Particularly mass transfer is more difficult to measure accurately at high spatial resolution, compared to heat transfer [5,11]. As a result, detailed conjugate experiments for forced convective drying of (un)saturated porous materials (e.g. [11]) are very scarce, as acknowledged by other researchers $[13,32,33]$. Such experiments are still an active topic of ongoing research (e.g. [17]). Finally, note that the need for detailed modelling of convective boundary conditions, e.g. by means of conjugate modelling, is strongly dependent on the drying behaviour of the porous material and is especially relevant during the CDRP and the transition to the DDRP, i.e. when the surface is (partially) wet, since then the air flow mainly determines the drying rate.

\section{Results and discussion}

\subsection{Drying process}

For the analysis of convective drying of a capillary-saturated porous material (see section 3), three different approaches to model the convective boundary conditions are compared: (1) conjugate modelling of heat and mass transport in the air flow and the porous material, as described in section 2, which will be referred to as the "conjugate approach" and which does not require the use of CTCs; (2) spatially-varying CTCs along the surface, where the CHTC is obtained from a CFD simulation, by only accounting for heat transfer, and where the CMTC is obtained from the CHTC by means of the heat and mass transfer analogy (see section 4.3), which will be referred to as the "CFD-analogy approach"; (3) spatially and temporally constant CTCs, namely the surfaceaveraged CTC values from the CFD-analogy approach, which will be referred to as the "constant CTCs approach". The CTCs for these approaches are presented in detail in section 4.2.

The overall dimensionless drying rates $\left(\mathrm{g}_{\mathrm{v}, \mathrm{w}} / \mathrm{g}_{\mathrm{v}, \mathrm{w}, \mathrm{CDRP}}\right)$ of the three approaches are shown as a function of dimensionless time $\left(t / t_{\text {tot }}\right)$ in Figure 3, where the total simulation time $\left(t_{\text {tot }}\right)$ is 15 days. As a reference drying rate, the drying rate during the CDRP $\left(\mathrm{g}_{\mathrm{v}, \mathrm{w}, \mathrm{CDRP}}\right)$, as obtained from the constant CTCs approach, is chosen. For the conjugate and CFD-analogy approaches, also the drying rates at specific locations on the porous-material surface are shown, namely at $\mathrm{x}=0,0.25$ and $0.5 \mathrm{~m}$. The surface temperatures $\left(\mathrm{T}_{\mathrm{w}}\right.$, in $\left.{ }^{\circ} \mathrm{C}\right)$ are shown in Figure 4 , together with the relative humidity at the surface $\left(\mathrm{RH}_{\mathrm{w}}\right)$. For the conjugate and CFD-analogy approaches, again the values at $\mathrm{x}=0,0.25$ and $0.5 \mathrm{~m}$ are reported. Contour plots of these dimensionless drying rates and the relative humidity at the surface as a function of dimensionless time and location on the surface are shown in Figure 5 for the conjugate approach. 
Defraeye T., Blocken B., Carmeliet J. (2012), Analysis of convective heat and mass transfer coefficients for convective drying of a porous flat plate by conjugate modelling, International Journal of Heat and Mass Transfer 55 (1-3), 112-124. http://dx.doi.org/10.1016/j.ijheatmasstransfer.2011.08.047

First the overall drying behaviour is discussed. A CDRP can clearly be distinguished for the constant CTCs approach, where the surface temperature approximately equals the wet bulb temperature. For the two other approaches, the surface-averaged drying rates show a much shorter CDRP, which is found to be related to the two-dimensional drying effect: the surface near the leading edge dries out first and quickly, while the remaining part of the surface dries out later. As a result, both CDRP and DDRP are found simultaneously at the surface, depending on the location on the surface, leading to a lower surface-averaged drying rate. A CDRP can also be distinguished at specific locations on the surface (Figure 3 and Figure 5), as discussed in detail below, where its duration increases with the distance from the leading edge. As the surface-averaged CTCs from the CFDanalogy approach equal those of the constant CTCs approach, the significant difference in drying behaviour between both indicates that accounting for spatially-varying convective boundary conditions is relevant here. Furthermore, when comparing the results of the CFD-analogy approach and the conjugate approach, the temporal variation of these convective boundary conditions also seems to affect the drying behaviour, indicating that the CTCs are also temporally-varying (see section 4.2).

The influence of spatial and temporal variation of the convective boundary conditions on the drying behaviour can be analysed more in detail when comparing the results of the conjugate and CFD-analogy approaches at different locations on the surface. The leading-edge effect can clearly be distinguished in Figures 3-5 and also in Figure 6, where the drying fronts $(\mathrm{RH} \approx 100 \%)$ inside the porous material are shown as a function of time for both approaches. Such leading-edge effects were previously reported by Masmoudi and Prat [12], Oliveira and Haghighi [32], Suresh et al. [33] and Murugesan et al. [13]. The higher drying rates close to the leading edge result from the small thermal and moisture boundary-layer thicknesses here. Furthermore, the drying rate at each location shows a distinct peak at a specific time. These peaks approximately correspond with the moment where the surface dries out locally ( $\mathrm{RH}<100 \%$, see Figure $4-5$ ) and can be explained as follows. As the material surface dries out progressively from the leading edge on, the amount of moisture transferred from the porous material into the moisture boundary layer above the "dry" surface part of the porous material is very limited as it is in the DDRP. Thereby, relatively dry air approaches the drying front at the surface, i.e. the separation between the dried-out and still wet part of the surface, by which the drying front acts as if it is the apparent start of a leading edge of a wet surface, resulting in locally high drying rates here. As the drying front at the surface progresses downstream with time, this apparent leading edge also progresses downstream, creating peaks in the drying rate at each location at a certain time. These drying rate peaks are much less pronounced for the CFDanalogy approach, which indicates that these peaks are accompanied by a (temporal) change in CTCs, as will be shown in section 4.2. Nevertheless, the drying fronts inside the porous material of the conjugate and CFDanalogy approaches show a similar behaviour (Figure 6).

Comparing the drying process at different locations, as in Figure 3, can be difficult if the drying rates differ significantly in magnitude, where the drying process reflects on the duration of the CDRP and DDRP and the transition between both. A better comparison can be made by using a scaled drying rate $\left(\mathrm{g}_{\mathrm{v}, \mathrm{w}, \mathrm{SC}}\right)$ and drying time $\left(\mathrm{t}_{\mathrm{SC}}\right)$, which are scaled with the CDRP drying rate at a specific location $\left(\mathrm{g}_{\mathrm{v}, \mathrm{w}, \mathrm{CDRP}}\right)$ : 
Defraeye T., Blocken B., Carmeliet J. (2012), Analysis of convective heat and mass transfer coefficients for convective drying of a porous flat plate by conjugate modelling, International Journal of Heat and Mass Transfer 55 (1-3), 112-124. http://dx.doi.org/10.1016/j.ijheatmasstransfer.2011.08.047

$\mathrm{g}_{\mathrm{v}, \mathrm{w}, \mathrm{SC}}=\frac{\mathrm{g}_{\mathrm{v}, \mathrm{w}}}{\mathrm{g}_{\mathrm{v}, \mathrm{w}, \mathrm{CDRP}}}$

$\mathrm{t}_{\mathrm{SC}}=\mathrm{g}_{\mathrm{v}, \mathrm{w}, \mathrm{CDRP}} \mathrm{t}$

By applying this spatially-dependent scaling, $\mathrm{g}_{\mathrm{v}, \mathrm{w}, \mathrm{SC}}$ is equal to one during the CDRP for all locations on the surface and the surface area below the drying rate curve remains to represent the amount of water which evaporated from the porous material at a specific location. These scaled curves are presented in Figure 7 for the conjugate and CFD-analogy approach as a function of time at different locations, where also the average scaled drying rate of the porous material is shown. Further away from the leading edge, the peaks at the transition between CDRP and DDRP clearly become more pronounced for the conjugate approach, where for the CFDanalogy approach, the peaks show a maximum at $\mathrm{x} \approx 0.1 \mathrm{~m}$.

Note that, due to the two-dimensional drying behaviour, the expression CDRP not strictly implies anymore that the entire material temperature is equal to the wet bulb temperature, but only that the RH at a specific location of interest is $100 \%$ and that the drying rate here is quasi constant. Since the surface temperatures during this CDRP are however approximately equal to the wet bulb temperature for the conjugate and CFD-analogy approaches at all locations (Figure 4), the influence of thermal inhomogeneities, as some parts of the surface dry out faster than others, on the predicted surface temperature is rather limited. Furthermore, the overall CDRP drying rates are approximately equal for all three approaches (Figure 3). Since the CDRP drying rate only depends on the convective boundary conditions (approach flow conditions and CTCs), the CTCs during the CDRP should therefore also be approximately the same for all three approaches, as will be shown in the next section.

\subsection{CTCs}

The conjugate approach does not require CTCs to represent the convective boundary conditions but it allows calculating the CTCs a-posteriori, by which their temporal and spatial variability can be identified. In Figure 8, the CTCs at different locations on the surface $(\mathrm{x}=0,0.25$ and $0.5 \mathrm{~m})$ are presented as a function of dimensionless time for all three approaches, where the CTCs of the constant CTCs approach (i.e. the surfaceaveraged values from CFD, combined with the analogy) are: $\mathrm{CHTC}=5.34 \mathrm{~W} / \mathrm{m}^{2} \mathrm{~K}, \mathrm{CMTC}=3.77 \times 10^{-8} \mathrm{~s} / \mathrm{m}$. In Figure 9, the CTC distributions over the surface are shown for all three approaches, where for the conjugate approach the CTCs at different times are given.

A distinct spatial CTCs variation can be noticed in these figures for the conjugate and CFD-analogy approaches, attaining higher values closer to the leading edge. From the conjugate approach results, a distinct temporal variability of the CTCs can also be noticed, especially when going from CDRP to DDRP so when the surface locally dries out, as indicated by the peaks in the CTCs in Figure 8. During the CDRP and the DDRP, the CTCs at a certain location remain approximately constant, but the magnitude of the CTCs increases from CDRP to DDRP (Figure 8). The CTCs of the conjugate approach agree well with the CTCs from the CFD-analogy approach during the CDRP, which indicates that the heat and mass transfer analogy appears to be valid during the CDRP but only to a lesser extent during the DDRP. The mismatch in the shape of the peaks of CHTCs and CMTCs (Figure 8) indicates that the heat and mass transfer analogy is also not valid during the transition from 
Defraeye T., Blocken B., Carmeliet J. (2012), Analysis of convective heat and mass transfer coefficients for convective drying of a porous flat plate by conjugate modelling, International Journal of Heat and Mass Transfer 55 (1-3), 112-124. http://dx.doi.org/10.1016/j.ijheatmasstransfer.2011.08.047

CDRP to DDRP. The validity of the analogy is discussed in detail in section 4.3. In Figure 9, the mismatch of CHTCs and CMTCs during this transition can also be noticed since the CMTCs show a distinct peak at a certain location on the surface, for a specific moment in time, whereas the CHTCs show a rather smooth decay at these locations. Figure 9 also indicates a strong temporal variability within the spatial CTCs variation over the surface. The temporal CTC variation indicates that CTCs are not only intrinsically related to the specific flow field, which is responsible for the spatial CTC variation, but that they are also dependent on the temperature and moisture distribution in the flow field (boundary layer) and at the air-porous material interface. Note however that their impact on the drying rate is much less important during the DDRP, as the internal vapour resistance of the porous material determines the liquid water removal rate from the material.

\subsection{Heat and mass transfer analogy}

The heat and mass transfer analogy allows estimating the CMTC directly out of the CHTC or vice versa, by relying on the similarity between the thermal and concentration boundary layers. An exact similarity however only applies under certain criteria, namely:

1. Heat and mass are both considered to be passive scalars, hence not influencing the flow field significantly, which is only valid for forced convective flows and for low mass transfer rates.

2. Heat and mass transfer are considered to be uncoupled, indicating that heat transfer does not influence mass transfer and vice versa. All fluid properties are however to some extent temperature- and (moisture) concentration-dependent and the influence of mass diffusion is accounted for in the heat conservation equation (see Eq.(8) and Eq.(10)).

3. Only convective heat and mass exchange with the environment occurs and no other heat or mass source terms are found at the surface, e.g. radiative absorption or droplet/water-film formation.

4. The temperature and concentration boundary conditions have to be analogous, e.g. constant flux conditions, in order to have a similar boundary-layer development.

5. The Lewis number $(\mathrm{Le}=\mathrm{Sc} / \mathrm{Pr})$ has to be unity. For air, the Prandtl $(\mathrm{Pr})$ and $\mathrm{Schmidt}$ number $(\mathrm{Sc})$ are however not equal $(\operatorname{Pr} \approx 0.74$ and $\mathrm{Sc} \approx 0.6$, resulting in $\mathrm{Le} \approx 0.81$ ).

To account for differences in $\operatorname{Pr}$ and Sc numbers, a modified version of the heat and mass transfer analogy, called the Chilton-Colburn analogy [34], was proposed:

$\frac{\mathrm{Nu}}{\mathrm{Sh}}=\left(\frac{\mathrm{Pr}}{\mathrm{Sc}}\right)^{1 / 3}$

where $\mathrm{Nu}$ is the Nusselt number and $\mathrm{Sh}$ is the Sherwood number. This analogy can also be rewritten as the ratio of the CTCs, referred to as the analogy factor $\left(\mathrm{AF}_{\mathrm{cc}}\right)$ :

$\mathrm{AF}_{\mathrm{cc}}=\frac{\mathrm{CMTC}}{\mathrm{CHTC}}=\left(\frac{\delta_{\mathrm{v}}}{\lambda_{\mathrm{g}}}\right)^{2 / 3} \frac{1}{\left(\mathrm{R}_{\mathrm{v}} \mathrm{T} \rho_{\mathrm{g}} \mathrm{c}_{\mathrm{p}, \mathrm{g}}\right)^{1 / 3}}$

This analogy factor is only a function of the properties of air, which are to some extent dependent on the temperature and concentration at the surface. For moist air, this factor is about $7.0 \times 10^{-9}$ at ambient conditions and can be assumed quasi constant (variations of a few percent with temperature and relative humidity) at temperatures well below $100^{\circ} \mathrm{C}$. The heat and mass transfer analogy is often not observed experimentally (e.g. [35]), since one or more similarity criteria are usually not satisfied, which is however not always acknowledged. 
Defraeye T., Blocken B., Carmeliet J. (2012), Analysis of convective heat and mass transfer coefficients for convective drying of a porous flat plate by conjugate modelling, International Journal of Heat and Mass Transfer 55 (1-3), 112-124. http://dx.doi.org/10.1016/j.ijheatmasstransfer.2011.08.047

In this study, the most relevant similarity criteria to be considered, which could clearly disprove the validity of the analogy here, are criterion 2 and 4.

For drying, another $\mathrm{CTC}$ ratio can be determined during the $\mathrm{CDRP}\left(\mathrm{AF}_{\mathrm{CDRP}}\right)$ from Eq.(3) [10], where the vapour pressure at the surface equals the saturation vapour pressure $\left(\mathrm{p}_{\mathrm{v}, \mathrm{w}, \mathrm{sat}}\right.$, function of $\left.\mathrm{T}_{\mathrm{w}}\right)$ since $\mathrm{RH}=100 \%$ :

$$
\mathrm{AF}_{\mathrm{CDRP}}=\frac{\mathrm{CMTC}}{\mathrm{CHTC}}=\frac{\left(\mathrm{T}_{\mathrm{w}}-\mathrm{T}_{\text {ref }}\right)}{-\mathrm{L}_{\mathrm{v}}^{\text {ref }}\left(\mathrm{p}_{\mathrm{v}, \mathrm{w}, \mathrm{sat}}\left(\mathrm{T}_{\mathrm{w}}\right)-\mathrm{p}_{\mathrm{v}, \text { ref }}\right)}
$$

If this $\mathrm{CTC}$ ratio $\left(\mathrm{AF}_{\mathrm{CDRP}}\right)$ is constant over the surface, the surface temperature during the CDRP becomes equal to the wet bulb temperature, if no radiative heat flows at the surface and (conductive) heat flows from the interior of the porous material are present. In contrast to $\mathrm{AF}_{\mathrm{cc}}, \mathrm{AF}_{\mathrm{CDRP}}$ is dependent on both the approach flow conditions ( $\mathrm{T}_{\mathrm{ref}}$ and $\left.\mathrm{p}_{\mathrm{v}, \mathrm{ref}}\right)$ and the temperature at the surface $\left(\mathrm{T}_{\mathrm{w}}\right)$, by which it can only be determined by numerical simulation (e.g. with a conjugate model) or by experiments. Usually, a CTC ratio is however imposed in HAM simulations (e.g. in constant CTCs or CFD-analogy approaches) by which the surface temperature can be determined from Eq.(32), based on the approach flow conditions.

The CMTCs at $\mathrm{x}=0.25 \mathrm{~m}$ are presented in Figure 10 as a function of time, calculated according to three different methods: (1) from the conjugate approach; (2) out of the CHTC of the conjugate approach, using the heat and mass transfer analogy (Eq.(31)), assuming constant air properties which results in a constant analogy factor; (3) out of the CHTC of the conjugate approach, using the analogy for drying during the CDRP (Eq.(32)). These CMTCs, calculated according to these three different methods, are shown in Figure 11 as a function of dimensionless time and location on the interface by means of a contour plot. With these CMTCs (and the CHTC of the conjugate approach), the corresponding analogy factors (CMTC/CHTC) are determined. Contour plots of these analogy factors as a function of time and location on the interface are shown in Figure 12. No contour plot of the heat and mass transfer analogy factor is shown since it is quasi constant, where only a very small variability is found due to the temperature and mass fraction dependency of the air properties (Eq.(31)). All three analogy factors at $\mathrm{x}=0.25 \mathrm{~m}$ are shown in Figure 12c.

All three methods give similar results for the CMTC and the analogy factors during the CDRP (Figure 10 and Figure 12c), which indicates that the heat and mass transfer analogy seems to be valid during the CDRP, as also found by Murugesan et al. [13] and Boukadida and Ben Nasrallah [35], and that the analogy for drying during the CDRP (Eq.(32)) also holds, which is however obvious. The good agreement for the heat and mass transfer analogy is related to the fact that the heat and mass transfer similarity criteria are approximately satisfied, except criterion 2, since heat and mass transfer are inherently coupled during the CDRP (Eq.(3)). Although the analogy is thereby principally not valid, the good agreement with the conjugate approach results however indicates that the influence of this criterion is small for the case considered. As a result of the good agreement for the CMTCs, the aforementioned analogy factors also agree well during the CDRP (Figure 12c). During the DDRP, all methods also agree quite well (both for CMTCs and analogy factors), although the heat and mass transfer analogy shows more discrepancies with the other methods. During the transition from CDRP to DDRP, significant discrepancies with the conjugate approach results can be found for both types of analogy. The 
Defraeye T., Blocken B., Carmeliet J. (2012), Analysis of convective heat and mass transfer coefficients for convective drying of a porous flat plate by conjugate modelling, International Journal of Heat and Mass Transfer 55 (1-3), 112-124. http://dx.doi.org/10.1016/j.ijheatmasstransfer.2011.08.047

discrepancies with the heat and mass transfer analogy during this transition and during the DDRP are mainly related to the fact that criterion 4 is not satisfied, as thermal and concentration boundary conditions are not similar anymore. Finally, it has to be noted that the largest discrepancies of the CMTCs and analogy factors obtained from the conjugate model with those obtained from the analogy for drying can be noticed in the region close to the leading edge during the DDRP and the transition from CDRP to DDRP (see Figure 10 and Figure 12).

\section{Conclusions}

In this study, convective drying of an unsaturated porous flat plate at low Reynolds numbers was analysed, where the focus was on the modelling of the convective boundary conditions. A conjugate model was developed, which accounts simultaneously for heat and mass transport in both the air flow and the porous material, by which it does not require knowledge of convective transfer coefficients (CTCs). Instead, the CTCs were determined aposteriori, hence identifying their spatial and temporal variability. The drying behaviour predicted by the conjugate model was compared with porous-material modelling using spatially and/or temporally constant CTCs. Also the validity of the heat and mass transfer analogy was analysed. Following conclusions were drawn:

1. Since CTCs varied spatially over the surface, the overall constant drying rate period (CDRP) was shorter, compared to the results when using constant CTCs, due to the quick onset of the decreasing drying rate period (DDRP) at the leading edge of the plate, resulting in lower overall drying rates. This leading-edge effect makes the drying behaviour in the porous material to be essentially two-dimensional.

2. By means of the conjugate model, a clear temporal CTC variation could be identified, where distinct peaks (maxima) in the drying rate appeared at the surface right before the surface dried out locally. This temporal CTC variation indicates that CTCs are not only intrinsically related to the specific flow field, but that they are also strongly dependent on the (varying) temperature and moisture distribution in the boundary layer and at the air-porous material interface.

3. A spatially-dependent scaling of the drying rate and drying time with the CDRP drying rate at each location was proposed, which allowed a better comparison of drying processes at different locations, which have drying rates that vary strongly in magnitude.

4. During the CDRP and the DDRP, the CTCs remained approximately constant but a distinct variation was noticed during the transition of CDRP to DDRP.

5. The heat and mass transfer analogy was found to be valid during the CDRP and only to a lesser extent during the DDRP, mainly because the similarity of thermal and concentration boundary conditions was not satisfied. Large discrepancies with the conjugate model results were however found during the transition of CDRP to DDRP. Note that in this study, most similarity criteria, required for the analogy to be valid, were satisfied (a.o. no radiation and no buoyancy), where in many drying processes they are not.

Conjugate modelling allows accounting for spatial and temporal variations in convective boundary conditions and thereby it circumvents the use of CTCs, which actually quantify the fluid-side heat and mass transfer in a rather simplified way. Conjugate modelling can thus be a valuable tool for the analysis of drying processes, leading to a more accurate identification of heterogeneous heat and moisture gradients inside the porous material. If conjugate modelling is not applied, it is strongly suggested to account for the spatial variation of the 
Defraeye T., Blocken B., Carmeliet J. (2012), Analysis of convective heat and mass transfer coefficients for convective drying of a porous flat plate by conjugate modelling, International Journal of Heat and Mass Transfer 55 (1-3), 112-124. http://dx.doi.org/10.1016/j.ijheatmasstransfer.2011.08.047

CTCs when performing porous-material modelling, for example by determining the CHTC by means of a CFD study and the corresponding CMTC with the analogy. The need for detailed modelling of convective boundary conditions is however strongly dependent on the moisture transport characteristics of the porous material: if the entire material quickly enters the DDRP, the internal porous-material vapour resistance determines the moisture removal rate from the material. Instead of accurate modelling of the convective boundary conditions, material characterisation related to liquid and vapour transport is critical here. In this case, a clear two-dimensional drying behaviour is not necessarily noticed and the need for conjugate modelling is alleviated. Moreover, simplifications which can be made to quantify the convective transfer rates, such as the use of the heat and mass transfer analogy, can be justified here since their impact on the obtained accuracy will be limited. The material type thus strongly determines the need for detailed CTC modelling.

\section{Acknowledgements}

This research is funded by the Government of Flanders. As a Flemish government institution, IWT-Flanders (Institute for the Promotion of Innovation by Science and Technology in Flanders) supports and stimulates industrial research and technology transfer in the Flemish industry. Their contribution is gratefully acknowledged. This sponsor had no involvement in: the study design, in the collection, analysis and interpretation of data; in the writing of the manuscript; and in the decision to submit the manuscript for publication.

\section{References}

[1] A.S. Mujumdar (Editor), Handbook of Industrial Drying, third ed., Taylor \& Francis Group, Boca Raton, USA, 2006.

[2] M. Prat, Percolation model of drying under isothermal conditions in porous media, International Journal of Multiphase Flow 19 (4) (1993) 691-704.

[3] J. Carmeliet, F. Descamps, G. Houvenaghel, A multiscale network model for simulating moisture transfer properties of porous media, Transport in Porous Media 35 (1999) 67-88.

[4] A.G. Yiotis, A.K. Stubos, A.G. Boudouvis, Y.C. Yortsos, A 2-D pore-network model of the drying of singlecomponent liquids in porous media, Advances in Water Resources 24 (3-4) (2001) 439-460.

[5] S. Ben Nasrallah, P. Perre, Detailed study of a model of heat and mass transfer during convective drying of porous media, International Journal of Heat and Mass Transfer 31 (5) (1988) 957-967.

[6] H. Janssen, B. Blocken, J. Carmeliet, Conservative modelling of the moisture and heat transfer in building components under atmospheric excitation, International Journal of Heat and Mass Transfer 50 (5-6) (2007) $1128-1140$.

[7] B. Blocken, T. Defraeye, D. Derome, J. Carmeliet, High-resolution CFD simulations for forced convective heat transfer coefficients at the facade of a low-rise building, Building and Environment 44 (12) (2009) $2396-2412$

[8] T. Defraeye, B. Blocken, J. Carmeliet, CFD analysis of convective heat transfer at the surfaces of a cube immersed in a turbulent boundary layer, International Journal of Heat and Mass Transfer 53 (1-3) (2010) 297-308. 
Defraeye T., Blocken B., Carmeliet J. (2012), Analysis of convective heat and mass transfer coefficients for convective drying of a porous flat plate by conjugate modelling, International Journal of Heat and Mass Transfer 55 (1-3), 112-124. http://dx.doi.org/10.1016/j.ijheatmasstransfer.2011.08.047

[9] T. Defraeye, B. Blocken, J. Carmeliet, Convective heat transfer coefficients for exterior building surfaces: Existing correlations and CFD modelling, Energy Conversion \& Management 52 (1) (2010) 512-522.

[10] X.D. Chen, S.X.Q. Lin, G. Chen, On the ratio of heat and mass transfer coefficient for water evaporation and its impact upon drying modeling, International Journal of Heat and Mass Transfer 45 (21) (2002) 4369-4372.

[11] A. Belhamri, J.P. Fohr, Heat and mass transfer along a wetted porous plate in an airstream, AIChE Journal 42 (7) (1996) 1833-1843.

[12] W. Masmoudi, M. Prat, Heat and mass transfer between a porous medium and a parallel external flow. Application to drying of capillary porous materials, International Journal of Heat and Mass Transfer 34 (8) (1991) 1975-1989.

[13] K. Murugesan, H.N. Suresh, K.N. Seetharamu, P.A. Aswatha Narayana, T. Sundararajan, A theoretical model of brick drying as a conjugate problem, International Journal of Heat and Mass Transfer 44 (21) (2001) 4075-4086.

[14] A. Erriguible, P. Bernada, F. Couture, M. Roques, Simulation of convective drying of a porous medium with boundary conditions provided by CFD, Chemical Engineering Research and Design 84 (2) (2006) 113-123.

[15] R. Younsi, D. Kocaefe, S. Poncsak, Y. Kocaefe, L. Gastonguay, CFD modeling and experimental validation of heat and mass transfer in wood poles subjected to high temperatures: a conjugate approach, Heat and Mass Transfer 44 (12) (2008) 1497-1509.

[16] Chr. Lamnatou, E. Papanicolaou, V. Belessiotis, N. Kyriakis, Conjugate heat and mass transfer from a drying rectangular cylinder in confined air flow, Numerical Heat Transfer, Part A: Applications 56 (5) (2009) 379-405.

[17] T. Defraeye, Convective heat and mass transfer at exterior building surfaces, $\mathrm{PhD}$ thesis, Catholic University of Leuven, Leuven, Belgium, 2011.

[18] Fluent Inc., Fluent 6.3 User's Guide, Lebanon - New Hampshire, USA, 2006.

[19] S. Whitaker, Simultaneous heat, mass, and momentum transfer in porous media: A theory of drying, Advances in Heat Transfer 13 (1977) 119-203.

[20] J.R. Philip, D.A. De Vries, Moisture movement in porous materials under temperature gradients, Transactions American Geophysical Union 38 (2) (1957) 222-232.

[21] A.V. Luikov, Heat and Mass Transfer in Capillary-Porous Bodies, first ed., Pergamon Press, New York, USA, 1966.

[22] S. Roels, J. Carmeliet, H. Hens, O. Adan, H. Brocken, R. Cerny, Z. Pavlik, C. Hall, K. Kumaran, L. Pel, R. Plagge, Interlaboratory comparison of hygric properties of porous building materials, Journal of Thermal Envelope and Building Science 27 (2004) 307-325.

[23] F. Dominguez-Munoz, B. Anderson, J.M. Cejudo-Lopez, A. Carrillo-Andres, Uncertainty in the thermal conductivity of insulation materials, Energy and Buildings 42 (11) (2010) 2159-2168.

[24] J.P. Monlouis-Bonnaire, J. Verdier, B. Perrin, Prediction of the relative permeability to gas flows of cement-based materials, Cement and Concrete Research 34 (2004) 737-744.

[25] F. Descamps, Continuum and discrete modelling of isothermal water and air flow in porous media, $\mathrm{PhD}$ thesis, Katholieke Universiteit Leuven, Belgium, 1997. 
Defraeye T., Blocken B., Carmeliet J. (2012), Analysis of convective heat and mass transfer coefficients for convective drying of a porous flat plate by conjugate modelling, International Journal of Heat and Mass Transfer 55 (1-3), 112-124. http://dx.doi.org/10.1016/j.ijheatmasstransfer.2011.08.047

[26] C. James, C.J. Simonson, P. Talukdar, S. Roels, Numerical and experimental data set for benchmarking hygroscopic buffering models, International Journal of Heat and Mass Transfer 53 (19-20) (2010) 36383654.

[27] P. Talukdar, S.O. Olutmayin, O.F. Osanyintola, C.J. Simonson, An experimental data set for benchmarking 1-D, transient heat and moisture transfer models of hygroscopic building materials. Part I: Experimental facility and material property data, International Journal of Heat and Mass Transfer 50 (23-24) (2007) 4527-4539.

[28] B. Blocken, J. Carmeliet, A review of wind-driven rain research in building science, Journal of Wind Engineering and Industrial Aerodynamics 92 (13) (2004) 1079-1130.

[29] R.B. Dean, Reynolds number dependence of skin friction and other bulk flow variables in two-dimensional rectangular duct flow, Transactions of the ASME: Journal of Fluids Engineering 100 (1978) 215-223.

[30] P. Talukdar, C.R. Iskra, C.J. Simonson, Combined heat and mass transfer for laminar flow of moist air in a 3D rectangular duct: CFD simulation and validation with experimental data, International Journal of Heat and Mass Transfer 51 (11-12) (2008) 3091-3102.

[31] J. Franke, A. Hellsten, H. Schlünzen, B. Carissimo, Best practice guideline for the CFD simulation of flows in the urban environment, COST Action 732: Quality assurance and improvement of microscale meteorological models, Hamburg, Germany, 2007.

[32] L.S. Oliveira, K. Haghighi, Conjugate heat and mass transfer in convective drying of porous media, Numerical Heat Transfer, Part A: Applications 34 (1998) 105-117.

[33] H.N. Suresh, P.A. Aswatha Narayana, K.N. Seetharamu, Conjugate mixed convection heat and mass transfer in brick drying, Heat and Mass Transfer 37 (2-3) (2001) 205-213.

[34] T.H. Chilton, A.P. Colburn, Mass transfer (absorption) coefficients, Industrial and Engineering Chemistry 26 (11) (1934) 1183-1187.

[35] N. Boukadida, S. Ben Nasrallah, Mass and heat transfer during water evaporation in laminar flow inside a rectangular channel - validity of heat and mass transfer analogy, International Journal of Thermal Sciences 40 (1) (2001) 67-81. 
Figure captions

Figure 1. Logarithm of liquid permeability of mineral plaster as a function the logarithm of the capillary pressure.

Figure 2. Computational model for numerical analysis with boundary conditions (not to scale).

Figure 3. Drying rate (scaled with $g_{v, w, C D R P}$ ) as a function of time (scaled with $t_{\text {tot }}$ ), for three convective boundary-modelling approaches: (a) the surface-averaged values of the three approaches (avg: surfaceaveraged); (b) the conjugate approach, including drying rates at specific locations; (c) the CFD-analogy approach, including drying rates at specific locations.

Figure 4. Relative humidity (b-d) and temperature (a-c) at the surface, as a function of time (scaled with $\left.t_{\text {tot }}\right)$, for three convective boundary-modelling approaches including results at specific locations for: (a-b) the conjugate approach (conj); (c-d) the CFD-analogy approach (CFD-an). The wet bulb temperature is indicated by WB temp.

Figure 5. Drying rate $\left(\mathrm{g}_{\mathrm{v}, \mathrm{w}} / \mathrm{g}_{\mathrm{v}, \mathrm{w}, \mathrm{CDRP}}\right)(\mathrm{a})$ and relative humidity $(\%)$ at the surface $(\mathrm{b})$ as a function of time (scaled with $t_{\text {tot }}$ ) and location on the surface (scaled with $L_{P M}$ ) for the conjugate approach. The CDRP and DDRP are indicated.

Figure 6. Drying fronts $(\mathrm{RH} \approx 100 \%)$ inside the porous material as a function of time (lines represent intervals of 5h) for: (a) the conjugate approach; (b) the CFD-analogy approach.

Figure 7. Scaled drying rate as a function of scaled time (both scaled with $\mathrm{g}_{\mathrm{v}, \mathrm{w}, \mathrm{CDRP}}$ at that specific location, Eqs.(28)-(29)) for the conjugate (a) and CFD-analogy approaches (b) at specific locations on the surface as well as the average drying rate.

Figure 8. CTCs ((a) CHTC, (b) CMTC) as a function of time (scaled with $t_{\text {tot }}$ ) for three convective boundary modelling approaches including the CTCs at specific locations for the conjugate and CFDanalogy approaches.

Figure 9. CTCs ((a) CHTC), (b) CMTC) as a function of location on the surface (scaled with $\mathrm{L}_{\mathrm{PM}}$ ), for three convective boundary modelling approaches including the CTCs at specific times for the conjugate approach.

Figure 10. CMTC, as a function of time (scaled with $t_{\text {tot }}$ ) at $x=0.25 \mathrm{~m}$, calculated according to three methods, namely by means of the conjugate approach, the heat and mass transfer analogy (Eq.(31)) and the CDRP analogy (Eq.(32)). 
Defraeye T., Blocken B., Carmeliet J. (2012), Analysis of convective heat and mass transfer coefficients for convective drying of a porous flat plate by conjugate modelling, International Journal of Heat and Mass Transfer 55 (1-3), 112-124. http://dx.doi.org/10.1016/i.ijheatmasstransfer.2011.08.047

Figure 11. CMTC, as a function of time (scaled with $t_{\text {tot }}$ ) and location on the surface (scaled with $\mathbf{L}_{P M}$ ), calculated according to three methods, namely by means of: (a) the conjugate approach; (b) the heat and mass transfer analogy (Eq.(31)); (c) the CDRP analogy (Eq.(32)). The CDRP and DDRP are indicated.

Figure 12. (a-b) Analogy factors (CMTC/CHTC ratio), as a function of time (scaled with $t_{\text {tot }}$ ) and location on the surface (scaled with $\mathrm{L}_{\mathrm{PM}}$ ), obtained from the CTCs calculated by: (a) the conjugate approach (Eq.(31)); (b) the CDRP analogy (Eq.(32)). The CDRP and DDRP are indicated. (c) Analogy factors as a function of time (scaled with $t_{\text {tot }}$ ) at $x=0.25 \mathrm{~m}$, calculated according to three methods, namely by means of the conjugate approach, the heat and mass transfer analogy (Eq.(31)) and the CDRP analogy (Eq.(32)). 
Defraeye T., Blocken B., Carmeliet J. (2012), Analysis of convective heat and mass transfer coefficients for convective drying of a porous flat plate by conjugate modelling, International Journal of Heat and Mass Transfer 55 (1-3), 112-124. http://dx.doi.org/10.1016/i.ijheatmasstransfer.2011.08.047

\section{Figures}

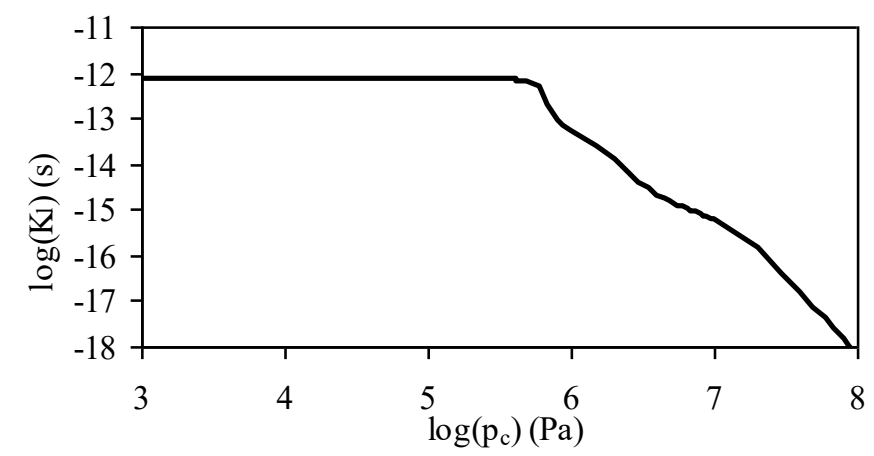

Figure 1. Logarithm of liquid permeability of mineral plaster as a function the logarithm of the capillary pressure. 
Defraeye T., Blocken B., Carmeliet J. (2012), Analysis of convective heat and mass transfer coefficients for convective drying of a porous flat plate by conjugate modelling, International Journal of Heat and Mass Transfer 55 (1-3), 112-124. http://dx.doi.org/10.1016/j.ijheatmasstransfer.2011.08.047

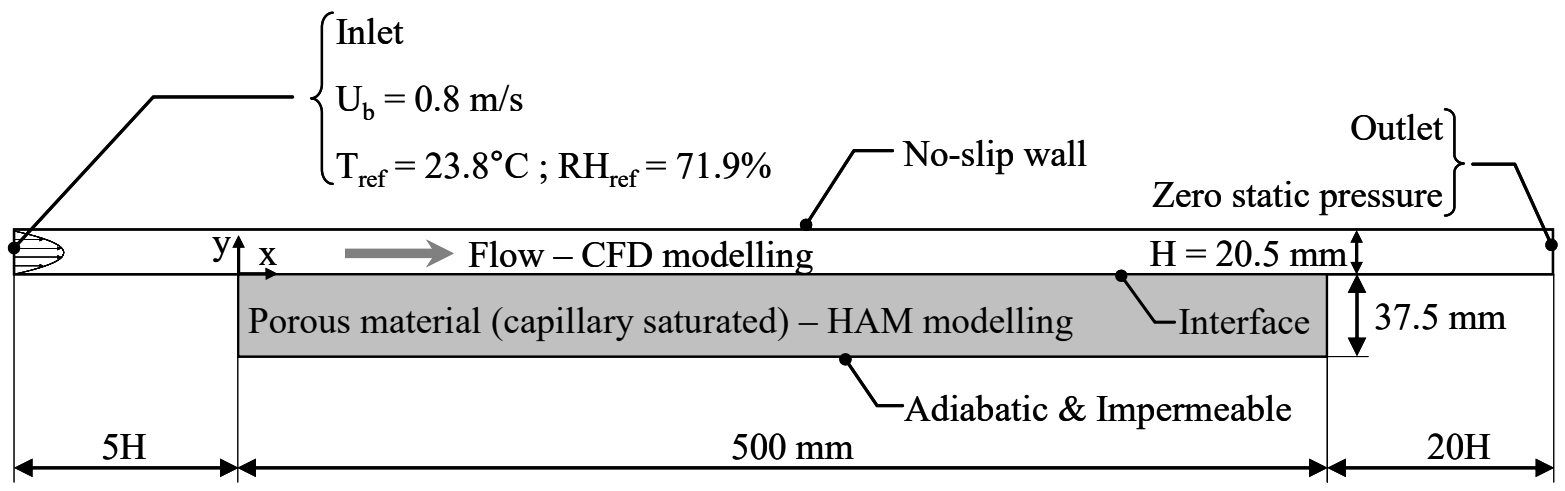

Figure 2. Computational model for numerical analysis with boundary conditions (not to scale). 
Defraeye T., Blocken B., Carmeliet J. (2012), Analysis of convective heat and mass transfer coefficients for convective drying of a porous flat plate by conjugate modelling, International Journal of Heat and Mass Transfer 55 (1-3), 112-124. http://dx.doi.org/10.1016/j.ijheatmasstransfer.2011.08.047
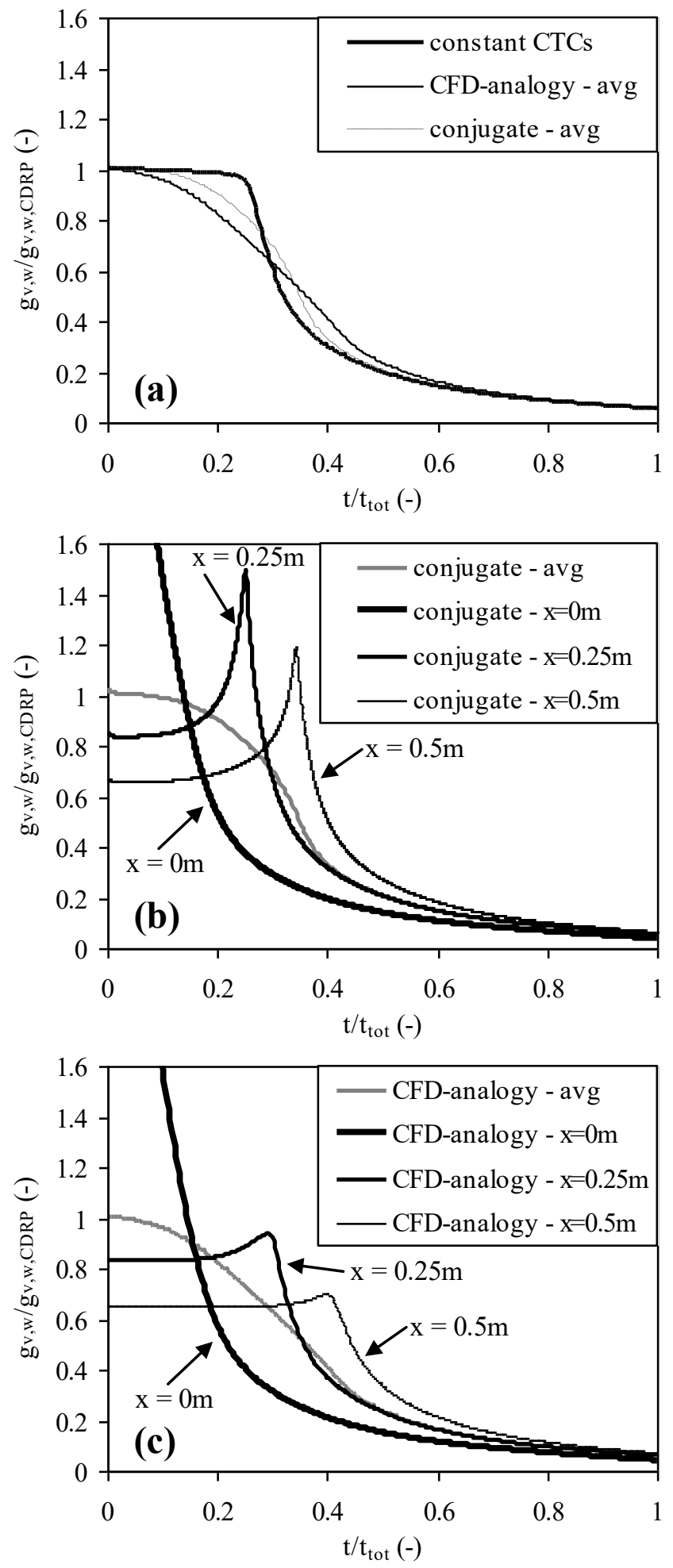

Figure 3. Drying rate (scaled with $g_{v, w, C D R P}$ ) as a function of time (scaled with $t_{t o t}$ ), for three convective boundary-modelling approaches: (a) the surface-averaged values of the three approaches (avg: surfaceaveraged); (b) the conjugate approach, including drying rates at specific locations; (c) the CFD-analogy approach, including drying rates at specific locations. 
Defraeye T., Blocken B., Carmeliet J. (2012), Analysis of convective heat and mass transfer coefficients for convective drying of a porous flat plate by conjugate modelling, International Journal of Heat and Mass Transfer 55 (1-3), 112-124. http://dx.doi.org/10.1016/j.ijheatmasstransfer.2011.08.047
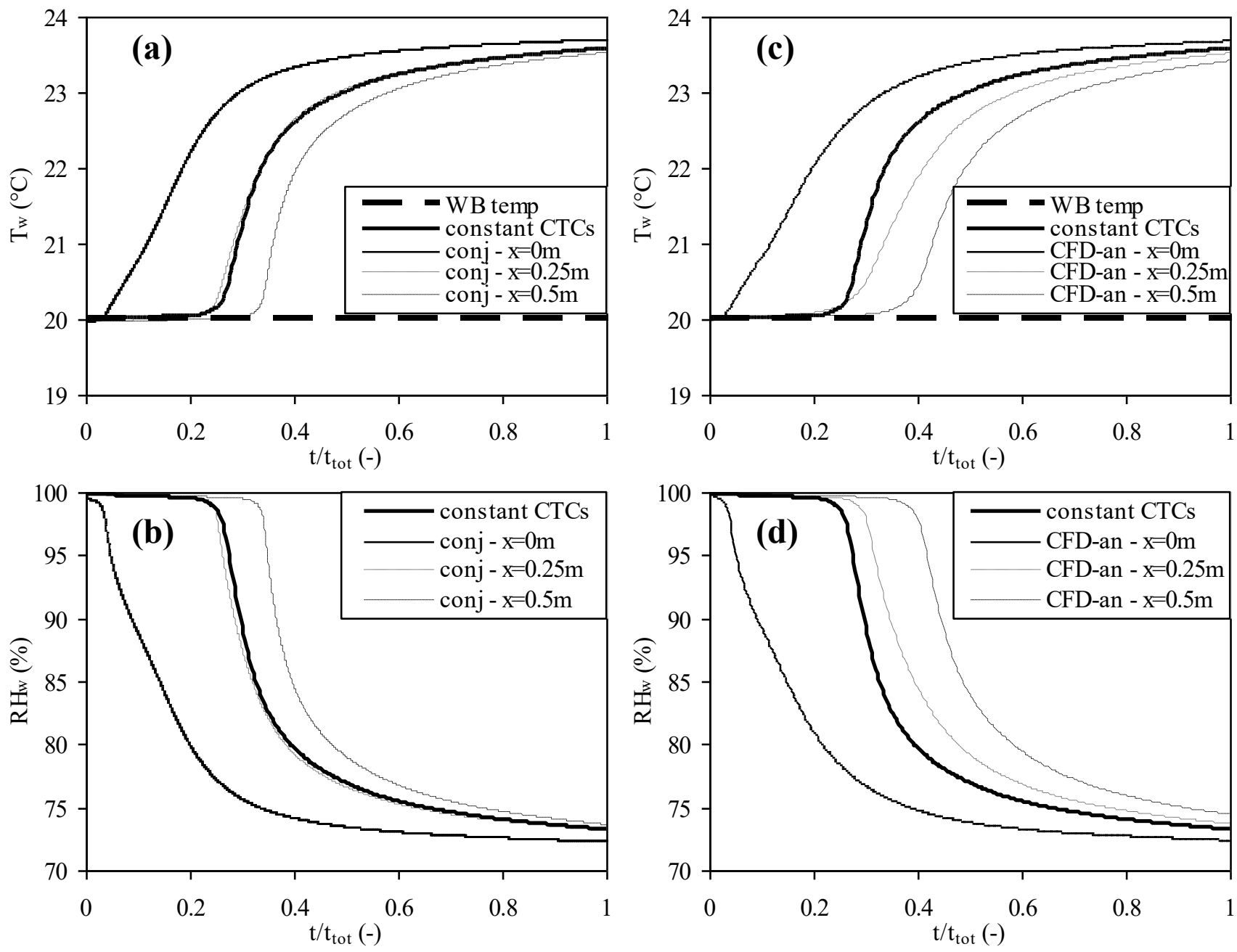

Figure 4. Relative humidity (b-d) and temperature (a-c) at the surface, as a function of time (scaled with $t_{\text {tot }}$, for three convective boundary-modelling approaches including results at specific locations for: (a-b) the conjugate approach (conj); (c-d) the CFD-analogy approach (CFD-an). The wet bulb temperature is indicated by WB temp. 
Defraeye T., Blocken B., Carmeliet J. (2012), Analysis of convective heat and mass transfer coefficients for convective drying of a porous flat plate by conjugate modelling, International Journal of Heat and Mass Transfer 55 (1-3), 112-124. http://dx.doi.org/10.1016/j.ijheatmasstransfer.2011.08.047
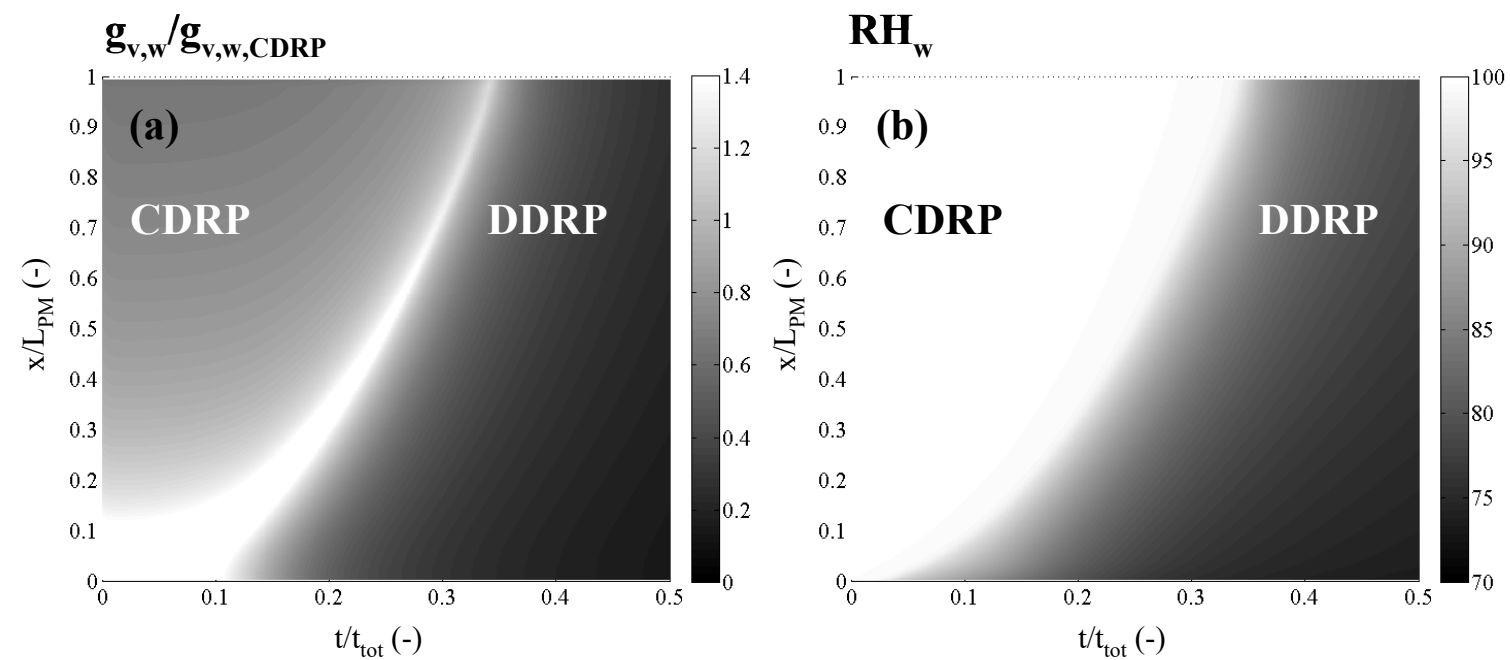

Figure 5. Drying rate $\left(\mathrm{g}_{\mathrm{v}, \mathrm{w}} / \mathrm{g}_{\mathrm{v}, \mathrm{w}, \mathrm{CDRP}}\right)$ (a) and relative humidity (\%) at the surface (b) as a function of time (scaled with $t_{t o t}$ ) and location on the surface (scaled with $L_{P M}$ ) for the conjugate approach. The CDRP and DDRP are indicated. 
Defraeye T., Blocken B., Carmeliet J. (2012), Analysis of convective heat and mass transfer coefficients for convective drying of a porous flat plate by conjugate modelling, International Journal of Heat and Mass Transfer 55 (1-3), 112-124. http://dx.doi.org/10.1016/j.ijheatmasstransfer.2011.08.047
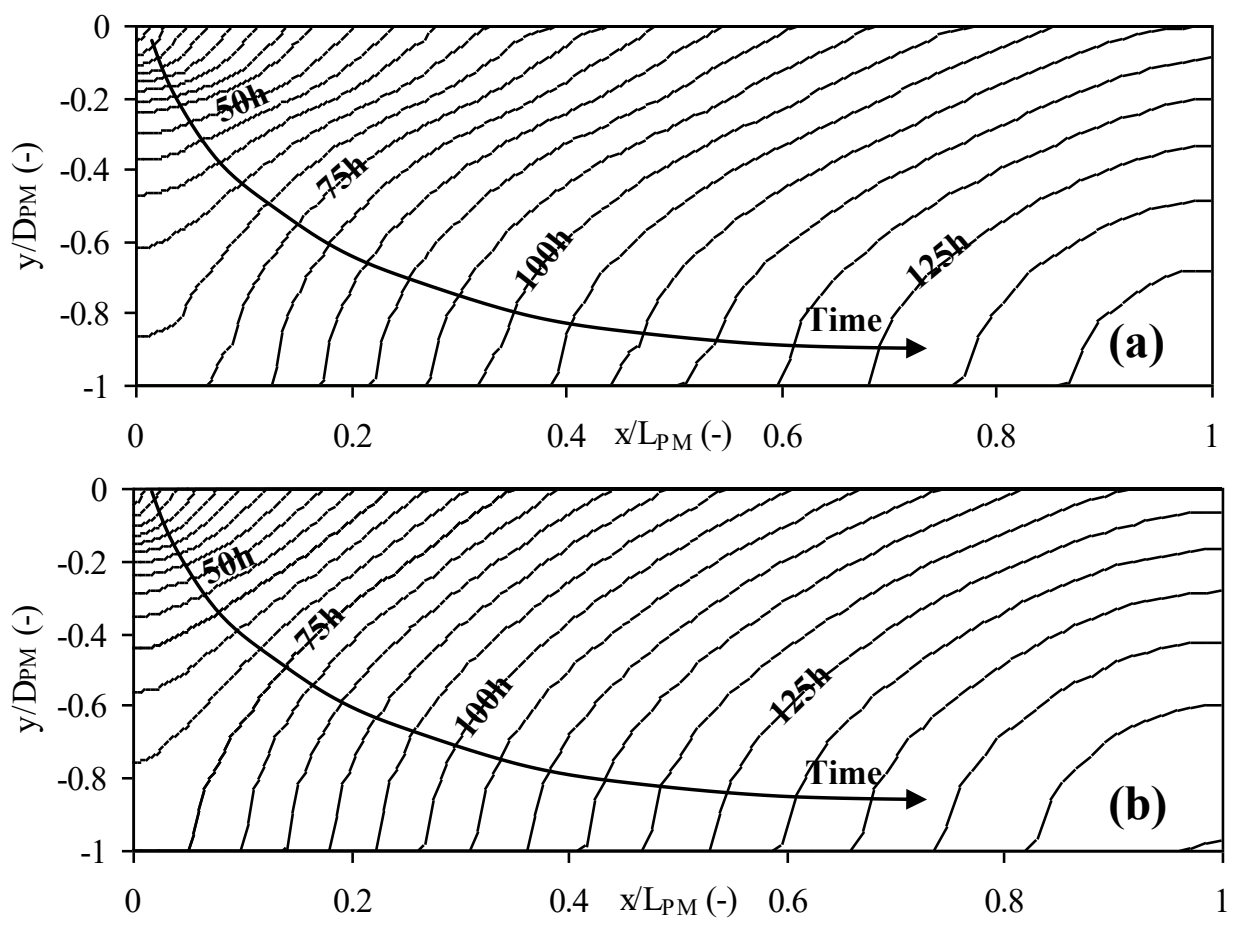

Figure 6. Drying fronts $(\mathrm{RH} \approx 100 \%)$ inside the porous material as a function of time (lines represent intervals of 5h) for: (a) the conjugate approach; (b) the CFD-analogy approach. 
Defraeye T., Blocken B., Carmeliet J. (2012), Analysis of convective heat and mass transfer coefficients for convective drying of a porous flat plate by conjugate modelling, International Journal of Heat and Mass Transfer 55 (1-3), 112-124. http://dx.doi.org/10.1016/j.ijheatmasstransfer.2011.08.047
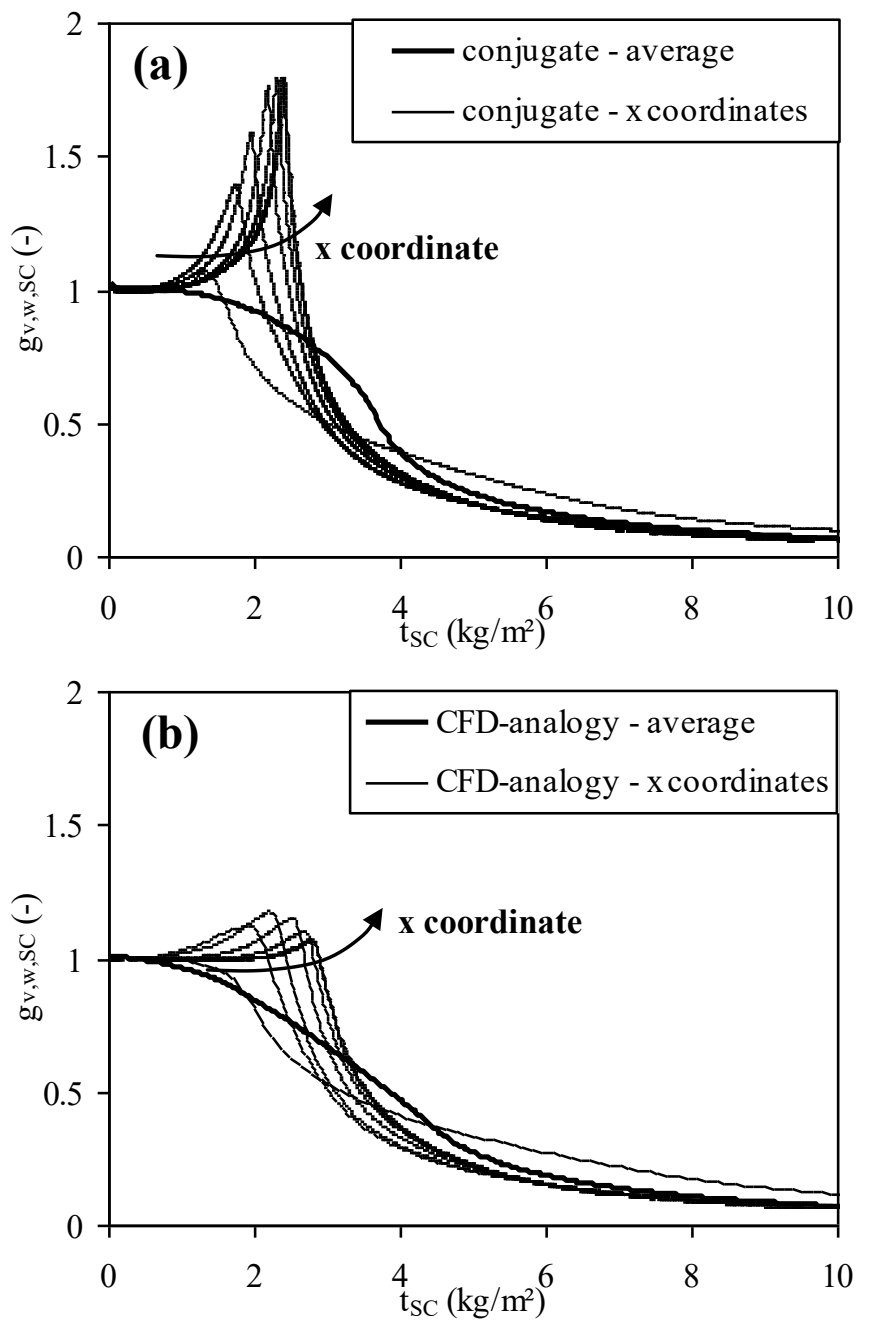

Figure 7. Scaled drying rate as a function of scaled time (both scaled with $\mathrm{g}_{v, w, C D R P}$ at that specific location, Eqs.(28)-(29)) for the conjugate (a) and CFD-analogy approaches (b) at specific locations on the surface as well as the average drying rate. 
Defraeye T., Blocken B., Carmeliet J. (2012), Analysis of convective heat and mass transfer coefficients for convective drying of a porous flat plate by conjugate modelling, International Journal of Heat and Mass Transfer 55 (1-3), 112-124. http://dx.doi.org/10.1016/j.ijheatmasstransfer.2011.08.047
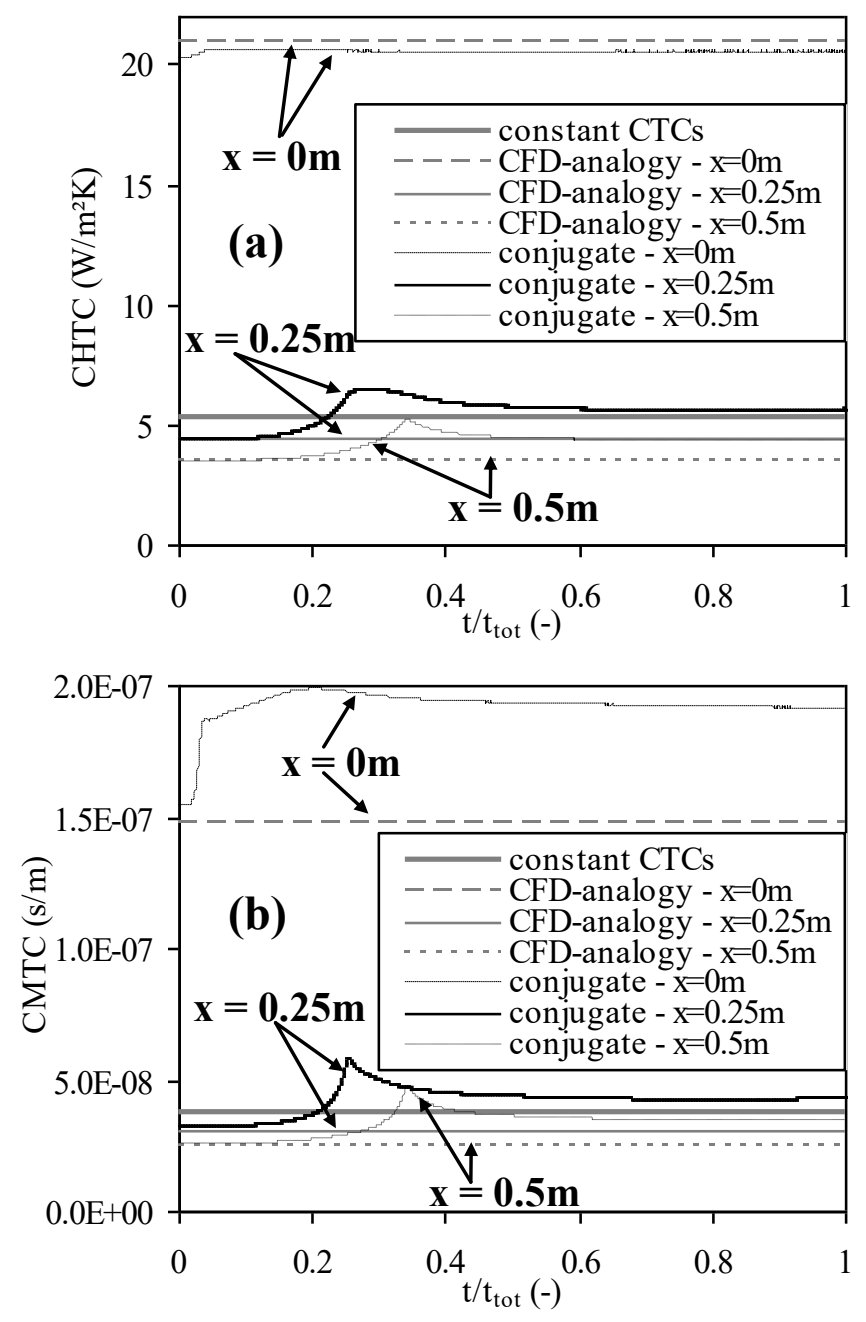

Figure 8. CTCs ((a) CHTC, (b) CMTC) as a function of time (scaled with $t_{\text {tot }}$ ) for three convective boundary modelling approaches including the CTCs at specific locations for the conjugate and CFDanalogy approaches. 
Defraeye T., Blocken B., Carmeliet J. (2012), Analysis of convective heat and mass transfer coefficients for convective drying of a porous flat plate by conjugate modelling, International Journal of Heat and Mass Transfer 55 (1-3), 112-124. http://dx.doi.org/10.1016/j.ijheatmasstransfer.2011.08.047
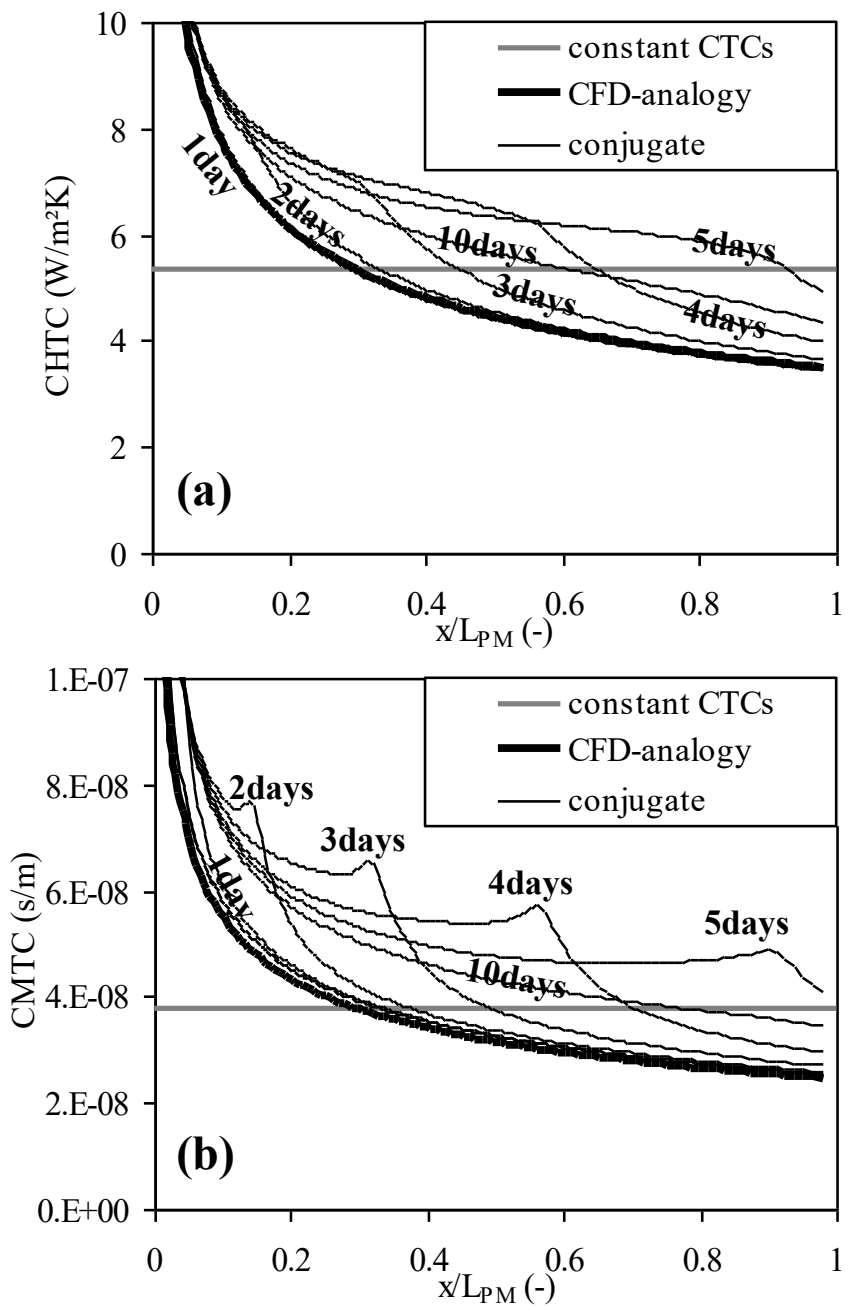

Figure 9. CTCs ((a) CHTC), (b) CMTC) as a function of location on the surface (scaled with $\mathrm{L}_{\mathrm{PM}}$ ), for three convective boundary modelling approaches including the CTCs at specific times for the conjugate approach. 
Defraeye T., Blocken B., Carmeliet J. (2012), Analysis of convective heat and mass transfer coefficients for convective drying of a porous flat plate by conjugate modelling, International Journal of Heat and Mass Transfer 55 (1-3), 112-124. http://dx.doi.org/10.1016/i.ijheatmasstransfer.2011.08.047

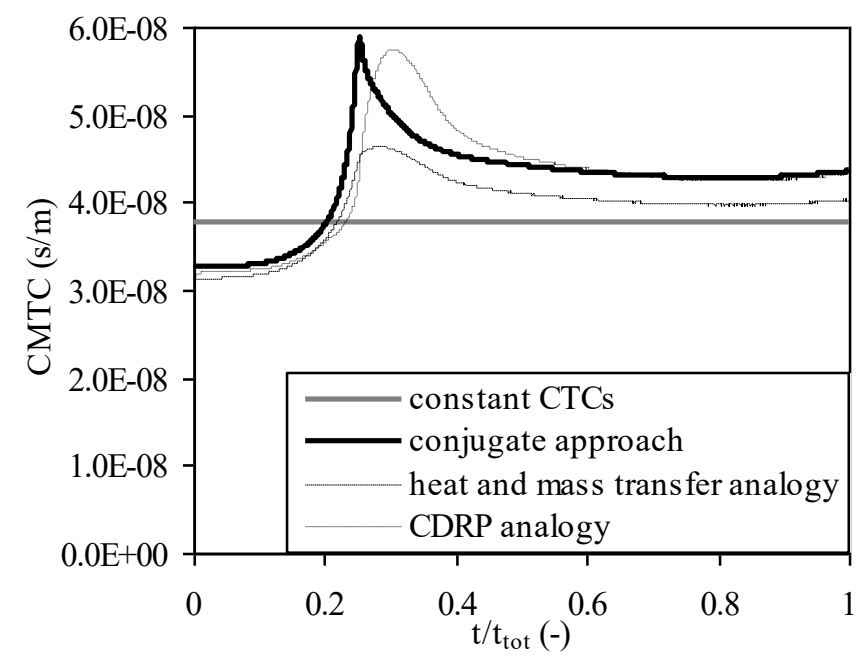

Figure 10. CMTC, as a function of time (scaled with $t_{\text {tot }}$ ) at $x=0.25 \mathrm{~m}$, calculated according to three methods, namely by means of the conjugate approach, the heat and mass transfer analogy (Eq.(31)) and the CDRP analogy (Eq.(32)). 
Defraeye T., Blocken B., Carmeliet J. (2012), Analysis of convective heat and mass transfer coefficients for convective drying of a porous flat plate by conjugate modelling, International Journal of Heat and Mass Transfer 55 (1-3), 112-124. http://dx.doi.org/10.1016/j.ijheatmasstransfer.2011.08.047

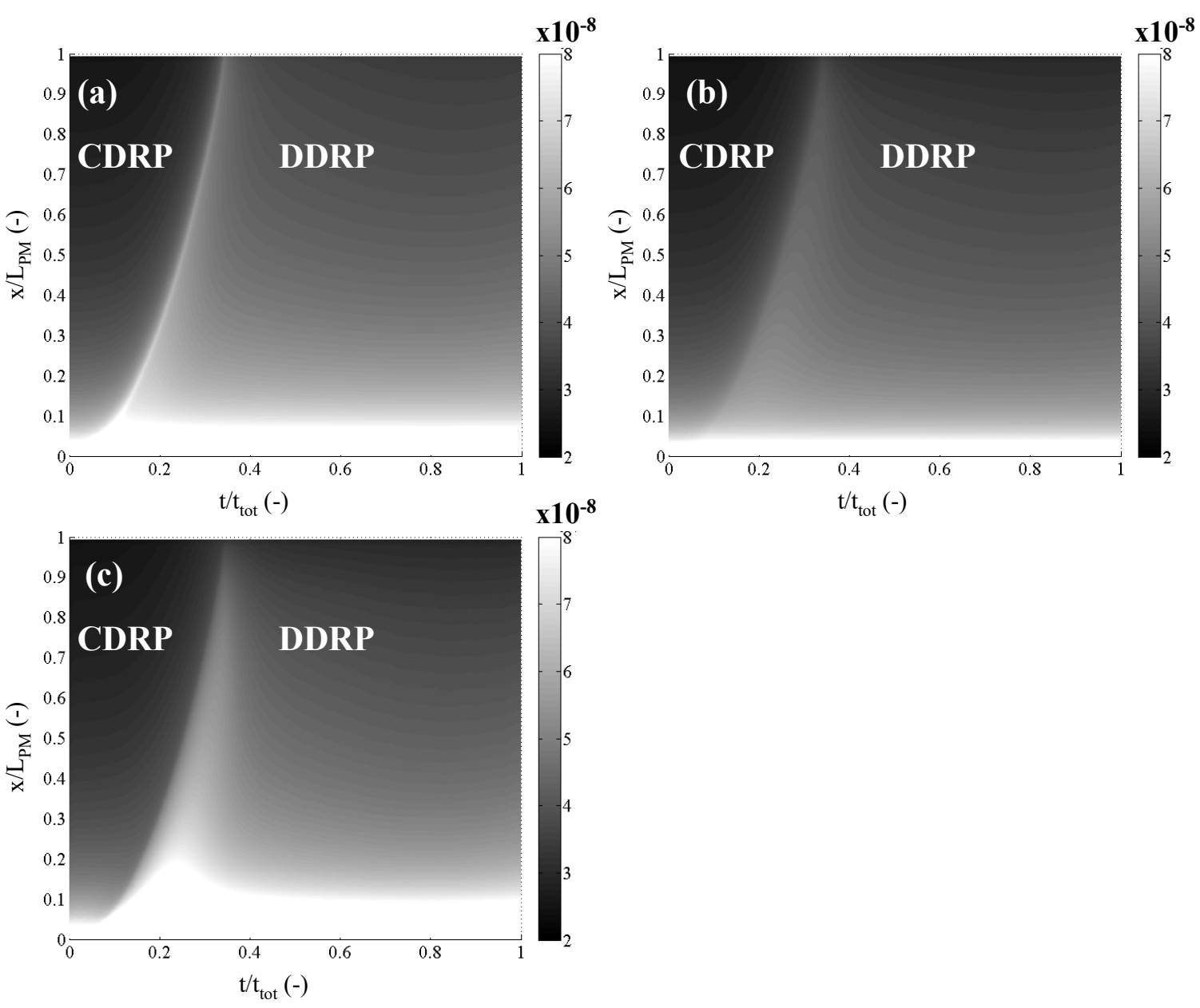

Figure 11. CMTC, as a function of time (scaled with $t_{\text {tot }}$ ) and location on the surface (scaled with $L_{P M}$ ), calculated according to three methods, namely by means of: (a) the conjugate approach; (b) the heat and mass transfer analogy (Eq.(31)); (c) the CDRP analogy (Eq.(32)). The CDRP and DDRP are indicated. 
Defraeye T., Blocken B., Carmeliet J. (2012), Analysis of convective heat and mass transfer coefficients for convective drying of a porous flat plate by conjugate modelling, International Journal of Heat and Mass Transfer 55 (1-3), 112-124. http://dx.doi.org/10.1016/j.ijheatmasstransfer.2011.08.047
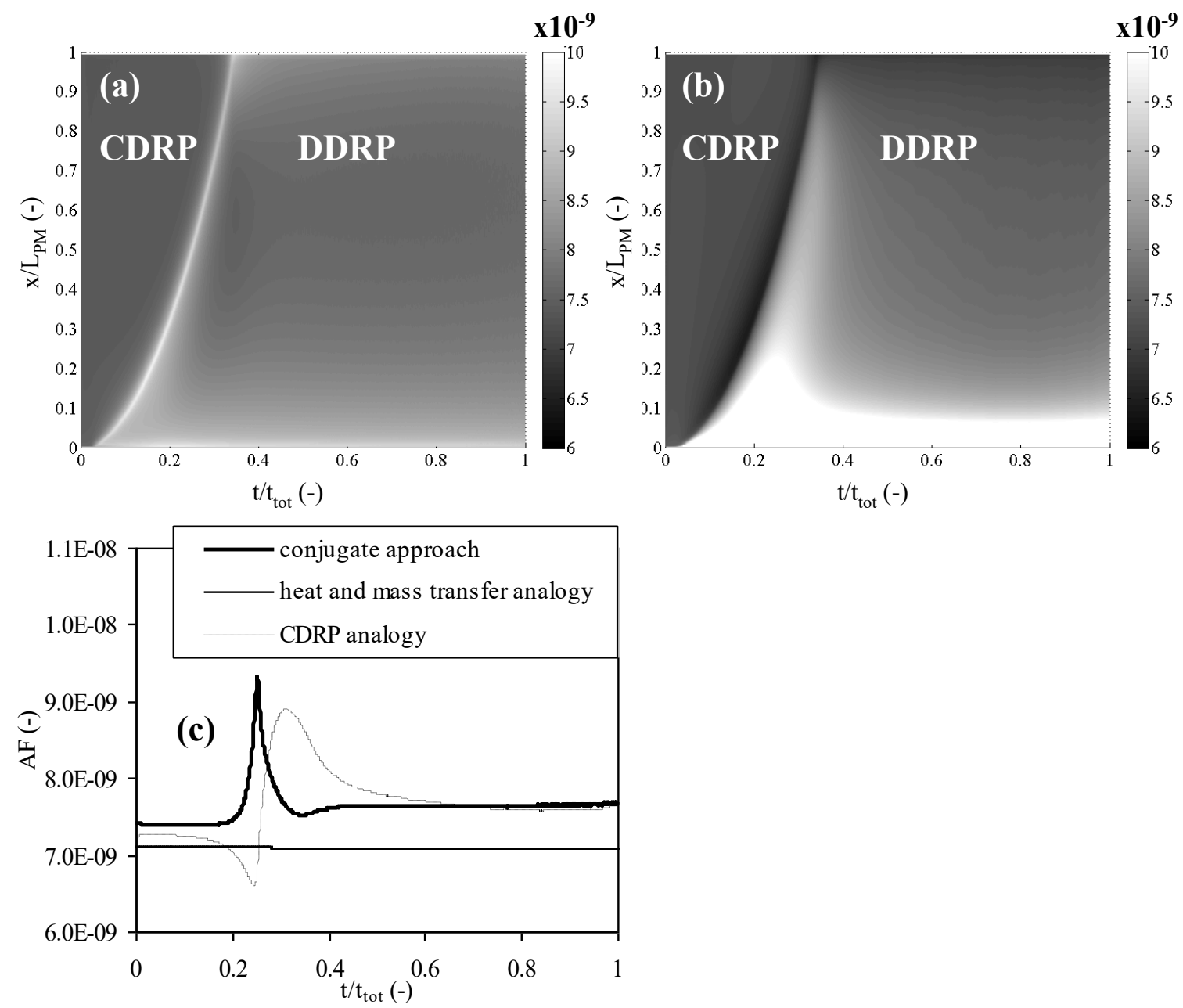

Figure 12. (a-b) Analogy factors (CMTC/CHTC ratio), as a function of time (scaled with $\mathrm{t}_{\text {tot }}$ ) and location on the surface (scaled with $\mathrm{L}_{\mathrm{PM}}$ ), obtained from the CTCs calculated by: (a) the conjugate approach (Eq.(31)); (b) the CDRP analogy (Eq.(32)). The CDRP and DDRP are indicated. (c) Analogy factors as a function of time (scaled with $t_{\text {tot }}$ ) at $x=0.25 \mathrm{~m}$, calculated according to three methods, namely by means of the conjugate approach, the heat and mass transfer analogy (Eq.(31)) and the CDRP analogy (Eq.(32)). 
Defraeye T., Blocken B., Carmeliet J. (2012), Analysis of convective heat and mass transfer coefficients for convective drying of a porous flat plate by conjugate modelling, International Journal of Heat and Mass Transfer 55 (1-3), 112-124. http://dx.doi.org/10.1016/j.ijheatmasstransfer.2011.08.047

\section{Tables}

Table 1. Material properties of mineral plaster, used for numerical modelling.

\begin{tabular}{lc}
\hline Property & Value \\
\hline $\mathrm{w}_{\mathrm{S}}\left(\mathrm{kg} / \mathrm{m}^{3} \mathrm{PM}\right)$ & 1615 \\
\hline $\mathrm{c}_{\mathrm{p}, \mathrm{s}}(\mathrm{J} / \mathrm{kgK})$ & 1050 \\
\hline$\lambda_{\mathrm{PM}}(\mathrm{W} / \mathrm{mK})$ & 1.2 \\
\hline$\mu_{\mathrm{dry}}(-)$ & 20 \\
\hline $\mathrm{w}_{\mathrm{cap}}\left(\mathrm{kg} / \mathrm{m}_{\mathrm{PM}}^{3}\right)$ & 126 \\
\hline$\delta_{\mathrm{v}}(\mathrm{s})$ & $\frac{2.61 \cdot 10^{-5}}{\mu_{\mathrm{dry}} \mathrm{R}_{\mathrm{v}} \mathrm{T}} \frac{1-\left(\mathrm{w}_{\mathrm{PM}} / \mathrm{w}_{\mathrm{cap}}\right)}{0.503\left(1-\left(\mathrm{w}_{\mathrm{PM}} / \mathrm{w}_{\mathrm{cap}}\right)\right)^{2}+0.497}$ \\
& $\mathrm{w}_{\text {cap }}\left[0.599\left(1+\left(4.08 \cdot 10^{-6} \mathrm{p}_{\mathrm{c}}\right)^{3}\right)^{-0.6667}+0.355\left(1+\left(9.58 \cdot 10^{-7} \mathrm{p}_{\mathrm{c}}\right)^{1.85}\right)^{-0.4596}+0.046\left(1+\left(2.04 \cdot 10^{-8} \mathrm{p}_{\mathrm{c}}\right)^{2.44}\right)^{-0.5910}\right]$ \\
\hline $\mathrm{W}_{\mathrm{PM}}\left(\mathrm{kg} / \mathrm{m}_{\mathrm{PM}}^{3}\right)$
\end{tabular}

